\title{
Review
}

\section{A review of hemorheology: Measuring techniques and recent advances}

\author{
Patrícia C. Sousa ${ }^{1}$, Fernando T. Pinho ${ }^{2}$, Manuel A. Alves ${ }^{1}$ and Mónica S.N. Oliveira, ${ }^{3 * *}$ \\ ${ }^{1}$ Departamento de Engenharia Química, CEFT, Faculdade de Engenharia da Universidade do Porto, \\ Rua Dr. Roberto Frias, 4200-465 Porto, Portugal \\ ${ }^{2}$ CEFT, Departamento de Engenharia Mecânica, Faculdade de Engenharia da Universidade do Porto, \\ Rua Dr. Roberto Frias, 4200-465 Porto, Portugal \\ ${ }^{3}$ James Weir Fluids Laboratory, Department of Mechanical and Aerospace Engineering, \\ University of Strathclyde, Glasgow G1 1XJ, United Kingdom
}

(Received September 29, 2015; final revision received November 11, 2015; accepted November 17, 2015)

\begin{abstract}
Significant progress has been made over the years on the topic of hemorheology, not only in terms of the development of more accurate and sophisticated techniques, but also in terms of understanding the phenomena associated with blood components, their interactions and impact upon blood properties. The rheological properties of blood are strongly dependent on the interactions and mechanical properties of red blood cells, and a variation of these properties can bring further insight into the human health state and can be an important parameter in clinical diagnosis. In this article, we provide both a reference for hemorheological research and a resource regarding the fundamental concepts in hemorheology. This review is aimed at those starting in the field of hemodynamics, where blood rheology plays a significant role, but also at those in search of the most up-to-date findings (both qualitative and quantitative) in hemorheological measurements and novel techniques used in this context, including technical advances under more extreme conditions such as in large amplitude oscillatory shear flow or under extensional flow, which impose large deformations comparable to those found in the microcirculatory system and in diseased vessels. Given the impressive rate of increase in the available knowledge on blood flow, this review is also intended to identify areas where current knowledge is still incomplete, and which have the potential for new, exciting and useful research. We also discuss the most important parameters that can lead to an alteration of blood rheology, and which as a consequence can have a significant impact on the normal physiological behavior of blood.
\end{abstract}

Keywords: hemorheology, blood viscosity, blood viscoelasticity, RBC deformability, RBC aggregation

\section{Introduction}

Understanding the rheological properties and flow dynamics of whole human blood is of great importance for the early detection, diagnosis and therapy of circulatory disorders as well as for the development of cardiovascular devices and prosthesis, such as blood pumps, heart valves or stents. With clear evidence that the rheological properties of blood are related with diseases, such as cardiovascular disorders (Dintenfass, 1979; Koenig et al., 1998), myocardial infarction (Jan et al., 1975; Marcinkowska-Gapinska et al., 2007), arterial hypertension (Lo Presti et al., 2014), diabetes mellitus (Le Devehat et al., 2004), cholesterol and triglyceride levels (Moreno et al., 2015) and sickle cell anaemia (Drasler et al., 1989), routine screening of hemorheological measurements could provide useful information for monitoring the development of such diseases.

Most investigations on rheological material functions concern steady shear measurements of whole blood. Other investigations have focused on transient and oscillatory

*Corresponding author; E-mail: monica.oliveira@strath.ac.uk flows, usually conducted under small amplitude deformation conditions (Vlastos et al., 1997; Picart et al., 1998; Yilmaz and Gundogdu, 2008). The flow of blood in physiological conditions typically involves large deformations, large deformation rates and periodic forcing with large amplitude (Caro et al., 1974) and consequently valuable information can be obtained from the characterization of blood under more extreme conditions, such as in large amplitude oscillatory shear flow (LAOS) (Sousa et al., 2013) or under conditions of extensional flow (Sousa et al., 2011) since these can be observed in diseased vessels (e.g. stenosis) and in vessel bifurcations. Despite the many advances of rheological techniques, which have confirmed the non-Newtonian nature of blood, current viscometer/ rheometer systems and measurement methodologies are still complex and blood viscosity measurements are not yet routinely implemented to provide relevant clinical information. On the other hand, emerging microfluidic technologies have been investigated for various clinical purposes including the analysis of blood samples from patients. The potential of these systems lies on their small characteristic length and time scales, which besides enhanced portability, avoid the need for time consuming 
blood treatment prior to the measurement, and reduce the required sample volume.

Over the years, there have been a number of excellent reviews on different topics on the broad subject of hemorheology (Replogle et al., 1967; Thurston, 1996; Thurston and Henderson, 2007; Yilmaz and Gundogdu, 2008). In the present review, we also focus on recent technical advances for the rheological characterization of blood using commercial instruments under less standard flow conditions (e.g. LAOS, extensional flows) and a diversity of novel micro-scale based techniques. The use of these technologies provided new data for the characterization of blood and new insights into its behavior under a broader range of flow conditions, which we compile and discuss in detail. We start by setting the background for those less experienced in the field with an introductory section, where the composition of blood is summarized, highlighting its constituents and functions, followed by a brief historical perspective of hemorheology, underlining the major developments in this area and finalizing with an upto-date summary of the most important rheological properties of blood. Section 2 focuses on the experimental techniques used to measure blood and plasma rheological properties, followed by a detailed review on hemorheology in Section 3, including recent data on transient rheological characterization. In Section 3.1 we discuss whole blood viscosity, in Section 3.2 we focus on its thixotropy and yield stress, and in Section 3.3 we address blood viscoelasticity. Finally, the concluding remarks and new directions for future investigation of blood rheology are outlined in Section 4.

\subsection{Blood constituents}

Blood is a concentrated suspension of corpuscles or formed elements, including red blood cells (RBC) or erythrocytes, white blood cells (WBC) or leukocytes, and platelets or thrombocytes in an intercellular liquid, the plasma (cf. Fig. 1) and accounts for 6-8\% of body weight in healthy humans (Waite, 2006). The density of blood under normal conditions is $1056 \pm 9 \mathrm{~kg} \cdot \mathrm{m}^{-3}$ (Eguchi and Karino, 2008).

Plasma is mainly composed of water at a concentration of approximately $90-92 \%$ by volume and several solutes, such as proteins (e.g. fibrinogen, albumin and cholesterol), lipids, glucids, and various electrolytes, essentially $\mathrm{Na}^{+}$, $\mathrm{K}^{+}, \mathrm{Ca}^{2+}$ and $\mathrm{Cl}^{-}$(Thiriet, 2008). Plasma accounts for approximately $55 \%$ of the blood volume (Thiriet, 2008) and has a density of about $1021 \mathrm{~kg} \cdot \mathrm{m}^{-3}$ (Shung, 2006). The molecular weight of plasma proteins can vary by approximately two orders of magnitude (Cokelet and Meiselman, 2007). Fibrinogen, which is essential in blood coagulation, occurs in different molecular weights, with the largest protein representing approximately $70 \%$ of the fibrinogen present in plasma (molecular weight of $340 \mathrm{kDa}$ ).

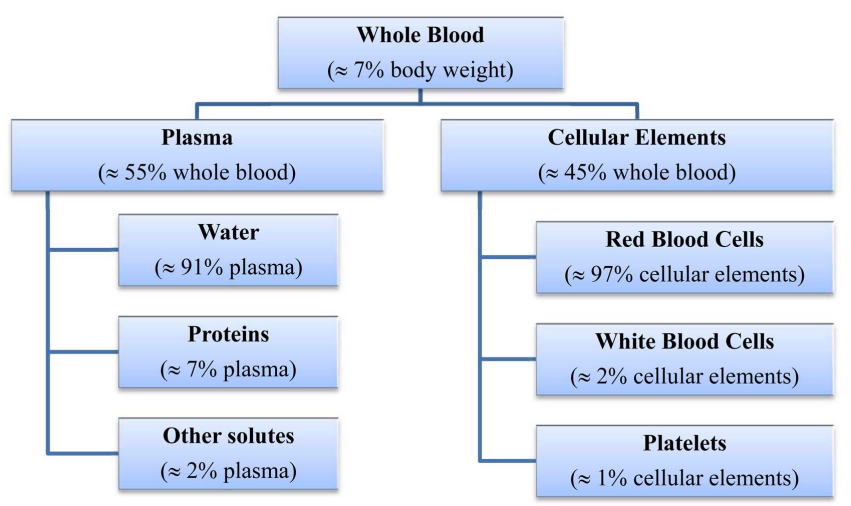

Fig. 1. (Color online) Main components of whole human blood and their typical volume concentrations.

The erythrocytes (density of $1,100 \mathrm{~kg} \cdot \mathrm{m}^{-3}$ (Thiriet, 2008)) are the most important cells in terms of their influence on blood properties and transport phenomena due to their overwhelming presence and multiple functions. The volume percentage of RBC in blood is called hematocrit, Hct, and in healthy humans, typically varies between $38-46 \%$ in women and $42-53 \%$ in men (Thiriet, 2008). The RBC are biconcave discs freely suspended in plasma, having typically $6-8 \mu \mathrm{m}$ in diameter and $2 \mu \mathrm{m}$ in thickness, as illustrated in Fig. 2. Inside the red blood cells there is a concentrated hemoglobin solution, which behaves as an incompressible viscous fluid. The cell membrane is made of a lipid bilayer and a cytoskeleton formed by protein molecules, and shows a complex rheological response with viscoelastic behavior (Puig-De-Morales-Marinkovic et al., 2007; Li et al., 2014). While at rest, RBC have a biconcave shape as shown in Fig. 2, aligning as ellipsoids with rotation of the membrane in arterial flow (Fischer et al., 1978) and deforming under the action of significant external forces, but returning to their original shape when the forces cease unless lysis of the cells occurs (Thiriet, 2008). The ability to adjust their shape reversibly is crucial for flowing through capillaries with diameters smaller than their cellular dimensions at rest (Secomb, 1987) and perform their main function of transporting nutrients to different parts of the body. It is well known that certain diseases, such as malaria and diabetes mellitus, are associated with reduced $\mathrm{RBC}$ deformation and may lead to
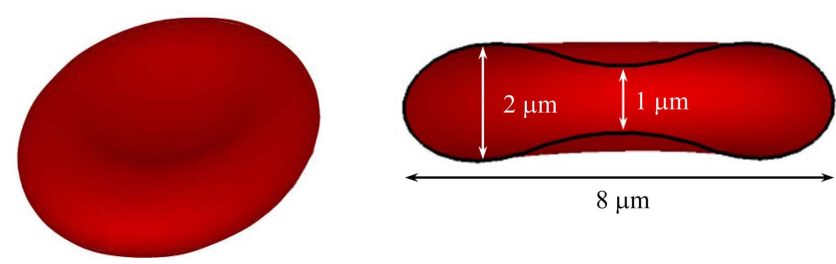

Fig. 2. (Color online) Schematic representation of a healthy red blood cell at rest and its typical dimensions. 
perfusion of peripheral tissues (Simchon et al., 1987), blockage of the capillaries or cause ischemia (Lee et al., 2009).

\subsection{Brief historical background of hemorheology}

Early hemorheology investigations reported blood as a Newtonian fluid (Langstroth, 1919; Pirofsky, 1953). Interestingly, Poiseuille's law was derived by the French physician Jean Léonard Marie Poiseuille, when he aimed to determine the pressure drop in capillary blood flow assuming a Newtonian fluid model (Sutera and Skalak, 1993). Non-Newtonian characteristics were observed early in the 20th century, with Hess (1915) reporting that although blood viscosity at high shear rates could be described using Newton's law of viscosity, the apparent shear viscosity increased as the pressure drop decreased. He then linked such phenomenon to the ability of RBC to form aggregates at low shear rates. This was arguably the first observation of the non-Newtonian rheological behavior of blood linked with its structure. The dependence of blood viscosity on flow conditions has later been quantified by means of steady rheological measurements, as reported in the investigations of Pirofsky (1953), Chien et al. (1966), Chien (1970) and Thurston (1979). The aggregating properties of RBC were first described by John Hunter in 1786 (Bishop et al., 2001).

During the second half of the 20th century the viscoelastic characteristics of blood were recognized in the pioneering work of Thurston (1972), who reported results of unsteady pipe flow with blood. Thurston found that blood stores elastic energy with increasing strain deformation, corroborating the previous work of Schmid-Schönbein et al. (1968), who reported the ability of RBC to form aggregates and to deform elastically. Later, the viscoelastic nature of blood was investigated in more detail in several works (Thurston, 1972; 1979; 1996). Most of the investigations on plasma rheology consider blood plasma to have a Newtonian behavior (Harkness, 1971; Koenig et al., 1998), but a few argue that it cannot be considered a Newtonian fluid (Sharma and Bhat, 1992; Brust et al., 2013).

In summary, the wealth of blood cells characteristics and their interactions result in a complex rheological behavior, such as viscoelasticity, shear-thinning and thixotropy (Thurston, 1979). In addition, blood has also been reported to have a small yield stress (Morris et al., 1987; Picart et al., 1998). Besides the rheological properties of blood and the physiological conditions (hematocrit, red blood cell deformability and aggregation), other parameters that affect blood dynamics are the blood pressure, the vessel shape and vessel wall properties. Another important physiological property that also affects hemorheology is the Fåhræus effect. Fåhræus (1929) investigated the flow of RBC suspensions with different aggregation levels in glass capillaries and observed that increasing the aggregation led to a radial migration of the cells toward the cen-

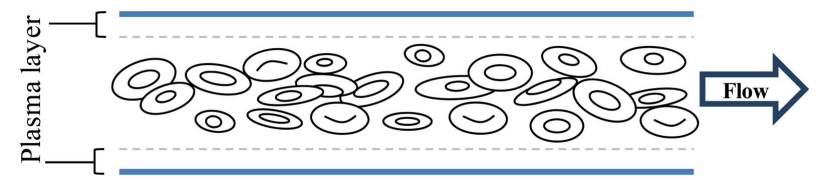

Fig. 3. (Color online) Sketch of the formation of a plasma enriched layer near the vessel walls and accumulation of RBC at the center of the vessel when blood is flowing (wall effect).

ter of the tube, and consequently to a cell-depleted layer near the vessel walls, as illustrated in Fig. 3.

The near-wall plasma enriched zone is thin, but impacts strongly on the relation between flow rate and pressure drop. The reduction of the red blood cell concentration near the wall leads to a decrease of the apparent blood viscosity and shear stress, and consequently may lead to inaccurate measurements when using small diameter capillaries for blood rheology characterization. In particular, below a critical diameter of $0.3 \mathrm{~mm}$, Fåhræus and Lindqvist (1931) found that the viscosity decreases markedly, as a consequence of a more effective radial migration of the red blood cells away from the vessel walls in relative terms, a behavior known as the Fåhræus-Lindqvist effect. In addition, the wall effect on blood viscosity was found to be negligible when the tube diameter is larger than about $0.4 \mathrm{~mm}$ (Fåhræus and Lindqvist, 1931). It is interesting to note that a similar phenomenon was previously observed by Bingham and Green (1919), albeit in qualitative terms, when they investigated the rheological behavior of paints.

\section{Experimental Methods for Rheological Measure- ments}

Different methods have been employed over the years to measure whole blood and plasma rheological properties, with most works focusing on the rheological characteristics under shear flow. We can divide the experimental methods for rheological measurements in two main groups, depending on their size: one using conventional devices, which we term "macro-scale" devices and the other using "micro-scale" devices. Conventional methods are the most common and most investigated, but the interest in microsystems for rheological measurements has been growing considerably over the last decade because of the small blood samples required and also because such devices can be cheap, portable and easily disposable, features which are important also for implementation in routine clinical diagnosis. Whatever the technique used, the ideal procedure should: (1) use a small blood sample that can be easily collected from the donor; (2) ensure no blood coagulation during collection and measurement, but avoiding the use of anticoagulant if possible; (3) be able to perform the measurement for a range of relevant temperatures, includ- 
ing normal body temperature, $T \cong 37^{\circ} \mathrm{C}$; (4) enforce simple and straightforward handling of blood sample; (5) provide known and controllable flow kinematics so that the principle of measurement is amenable to analytical mathematical solution (Muramoto and Nagasaka, 2011).

\subsection{Macro-scale rheological devices}

\subsubsection{Mechanical methods}

The characterization of blood rheology (e.g. shear viscosity, yield stress and viscoelastic properties) has been mostly based on mechanical methods, in which the fluid experiences a shear flow and the resistance to the fluid motion is measured. In particular, rotational rheometers are extensively used, with emphasis on the parallel plates, cone and plate and the coaxial cylinders or Couette geometries. In this section we focus on the experimental techniques for the measurement of blood and plasma shear viscosity as well as yield stress and viscoelastic properties of blood.

Blood and plasma shear viscosity: The foundations of blood rheology result from a multiplicity of experiments performed using a range of "classical" instruments: falling ball viscometer, capillary viscometer, tube viscometers and rotational rheometers (Bishop et al., 2001; Rosencranz and Bogen, 2006). Techniques such as the falling ball viscometer, or the capillary tube, were widely employed in early investigations (Rosencranz and Bogen, 2006). For example, early measurements of plasma viscosity were performed using a capillary viscometer, also known as Harkness viscometer (Harkness, 1971), which was recommended as a standard measuring method for plasma viscosity (International Committee for Standardisation in Haematology, 1984) due to the simple and lowcost set-up, as well as the small amount of sample required, and the short duration of the test. However, this method is particularly suited for measurement of the viscosity of Newtonian fluids. Currently, there are several commercially available instruments based on different principles and techniques, which yield identical results if used properly (Baskurt et al., 2009a). Commercially available rotational rheometers (Fig. 4a) are some of the most versatile and commonly used devices for rheological characterization under shear. This type of rheometers has seen important improvements over the years, but also presents some disadvantages for measuring blood rheological properties, especially if to be used in a medical context. These systems are, in general, bulky, complex to use, and timeconsuming. Issues related to the sedimentation of the cells and to the formation of a cell-depleted layer near the walls need to be carefully monitored to avoid erroneous measurements, particularly depending on the gap used for the measurement of blood rheology, which can be minimized
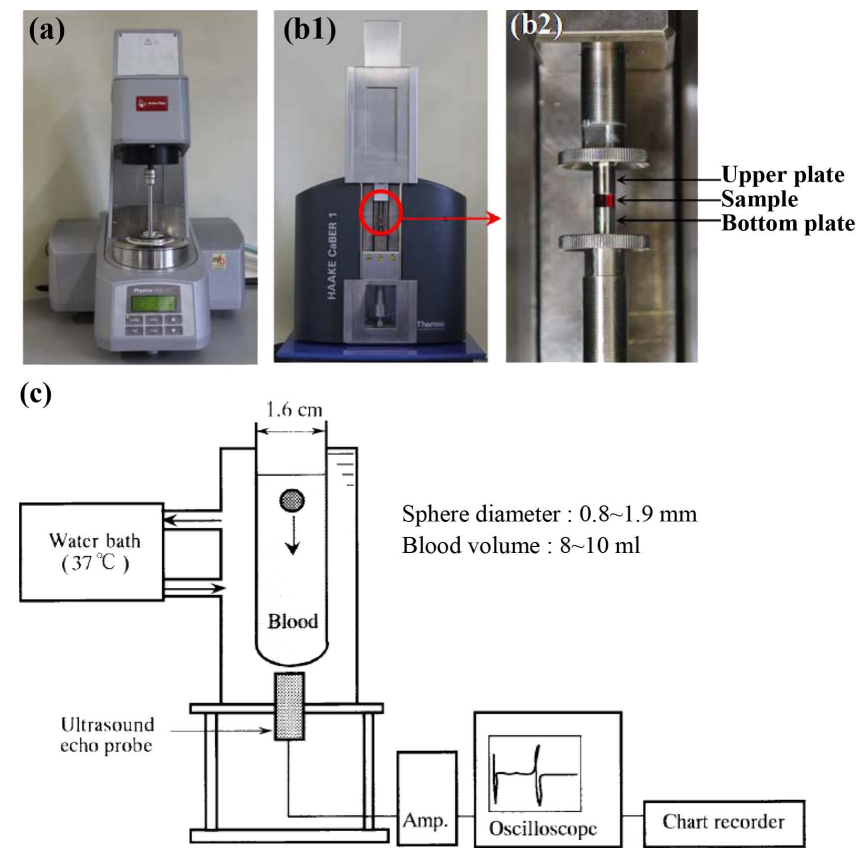

Fig. 4. (Color online) Examples of mechanical devices employed in rheological measurements of blood. (a) Rotational rheometer (Physica MCR301, Anton Paar). (b1) Capillary break-up extensional rheometer Haake ${ }^{\mathrm{TM}} \mathrm{CaBER}^{\mathrm{TM}} 1$ (Thermo Scientific). (b2) Zoomed view of the test section. The sample is placed in the space between the upper and the bottom plates. (c) Schematics of the falling-ball viscometer used by Eguchi and Karino (2008). Reprinted with permission from Eguchi and Karino (2008).

using roughened surfaces (Merrill, 1969; Sousa et al., 2013).

Most of the classic measurement systems require a relatively high volume of blood; usually more than $1 \mathrm{ml}$ is necessary depending on the apparatus used. In order to overcome this limitation, and reduce the measurement time, oscillating torsional viscometers have been proposed, making blood rheological tests faster, more direct and feasible (Mark et al., 2006; Eugster et al., 2007; Travagli et al., 2008). As an example, Eugster et al. (2007) developed an oscillating viscometer based on a glass capillary which only requires $7 \mu \mathrm{l}$ of blood for measuring blood viscosity.

Automatic tube-type viscometers have also been developed (Kim et al., 2000; Alexy et al., 2005a) including a system able to measure the whole blood viscosity within 2 minutes at shear rates ranging from 1 to $375 \mathrm{~s}^{-1}$ (Kim et al., 2000). A falling-ball viscometer (Fig. 4c), used to measure the shear viscosity of whole blood and RBC suspensions, demonstrated high sensitivity to changes in blood viscosity, and can be useful clinically for detecting abnormal blood viscosity values (Eguchi and Karino, 2008) and thus can potentially be converted into screening platforms (Mark et al., 2006), but require a significant sample volume. 
Yield stress: Different factors can affect the measurement of blood yield stress, namely the torque accuracy and sensitivity of the instrument used at low shear rates, the cell sedimentation and the plasma layer formation, which are particularly relevant at low shear rates due to the formation of cell aggregates. Most of the yield stress values reported in the literature were determined using an indirect technique by extrapolating rheological data obtained using a Couette-type rheometer. In order to avoid the wall slip phenomenon, Picart et al. (1998) used a Couette rheometer in which the measuring system had roughened surfaces. Blood yield stress was also measured using a settling technique (Charm and Kurland, 1967) and by recording stress relaxation curves (Benis and Lacoste, 1968), both of which are direct measurement techniques. The values of the blood yield stress reported in the literature present a significant variability, which can be attributed to donor-to-donor variability, but also to deficiencies of the different measurement methods used (Picart et al., 1998).

Viscoelastic properties of blood: Properties such as the storage $\left(G^{\prime}\right)$ and loss $\left(G^{\prime \prime}\right)$ moduli (or alternatively the viscous $\left(\eta^{\prime}\right)$ and elastic $\left(\eta^{\prime \prime}\right)$ components of the complex viscosity), are usually measured in small amplitude oscillatory shear flow (SAOS). In this type of experiment, a part of the measurement geometry oscillates to a preset maximum strain (an angle, typically small, in a rotational rheometer) and the time-dependent response is measured. The imposed strain is small in order to keep the sample microstructure unaffected, which allows probing the viscoelastic behavior in the linear regime. In addition to the geometries commonly used for measuring other rheological properties of blood, porous media have also been used to measure $G^{\prime}$ and $G^{\prime \prime}$. Porous media can exhibit tortuosity comparable to that of the vessels and were used to determine Maxwell relaxation times and to assess the importance of the blood elasticity relative to viscosity (Thurston and Henderson, 2006). However, in this case, the cell aggregation phenomenon occurs to a small extent due to the restricted space in the pores, thus affecting the measurement of the complex viscosity. It is known that for a tube dimension smaller than about ten RBC diameters the formation of a cell depletion layer affects significantly the measurements (Thurston and Henderson, 2006), which may well hinder rheological measurements with this type of device. It is important to note that the rheological measurements can be affected not only by the confinement size of the geometry used but also by the possible sedimentation of the RBC (Thurston and Henderson, 2007), and proper care should be taken to minimize these effects. The use of roughened surfaces is common to reduce wall slip and the formation of a cell free layer at the wall and procedures that involve a homogenization step have been proposed to minimize RBC sedimentation (Marton et al.,
2001; Lee et al., 2007; Sousa et al., 2013).

LAOS tests can be used in the measurement of the nonlinear viscoelastic response of blood, which can be associated with its internal structure. In LAOS (and SAOS), an oscillatory shear stress or strain is imposed to the sample and the other one is monitored, i.e. if the strain is imposed the shear stress is measured, and the viscous and elastic components of the viscoelastic sample are quantified. The imposed variable follows a sinusoidal evolution in time and for LAOS the corresponding response is no longer sinusoidal, containing higher harmonic contributions. The odd harmonics are related with the rheological response of the sample, while the even harmonics are due to experimental deficiencies (Ewoldt et al., 2008; Hyun et al., 2011). A technique commonly used to analyze the material response is the Fourier transform, which is used to determine the storage and loss moduli of the viscoelastic sample (Hyun et al., 2011).

The elastic properties of blood plasma have also been measured under uniaxial extensional flow (Brust et al., 2013). A capillary breakup extensional rheometer (CaBER), similar to the commercial apparatus illustrated in Fig. 4b, was employed to measure a characteristic relaxation time of blood in extensional flow. In this technique a fluid sample is placed between two circular plates, which are separated by a small gap. The plates are then separated to a final larger gap and the liquid thread thins spontaneously until the occurrence of breakup, under the combined action of capillary and extensional resisting forces, which for viscoelastic fluids is essentially a viscoelastic force. The diameter of the filament $(D(t))$ is monitored as function of time and for a viscoelastic fluid, the filament diameter decreases exponentially and the relaxation time of the fluid is determined by fitting the experimental data in the linear region of $\log D(t)$ as a function of time. The drawback is that for fluids having a low viscosity and small elasticity, the filament thinning is very rapid, inertia may not be negligible and it is difficult to monitor filament time evolution with good resolution under these conditions. In addition, in the final stage of the thinning process, the filament diameter is of the order of a few microns, which is comparable to the RBC dimensions, and can lead to inaccurate measurements for whole blood extensional rheology measurements.

\subsubsection{Optical methods}

An optical technique for measuring whole-blood viscosity based on laser-induced capillary waves was introduced by Muramoto and Nagasaka (2011). Pulsed YAG laser beams are used to heat the whole-blood sample and to generate a capillary wave, which is then detected by a diffracted probing laser beam at the heated region. The intensity of the diffracted probing beam is converted into viscosity and surface tension measurements of the blood 
sample. Despite the short time and the small sample volume required, a wide range of viscosities can be measured using this method.

Another method that was investigated involves fluorescent viscosity-sensitive dyes, referred to as molecular rotors (Haidekker et al., 2002). Due to their high sensitivity, spatial and temporal resolution, these molecular probes are a good alternative to mechanical methods for measuring blood plasma viscosities. Upon photoexcitation, the fluorescent molecules form twisted intramolecular charge transfer states. Photoexcitation leads to an electron transfer and the quantum yield of a molecule rotor increases with decreasing free volume of the solvent, which is related with viscosity. The emission intensity of molecular rotors depends on the viscosity of the solvent. In the measurements of whole blood viscosity, the use of fluorescent molecular rotors shows some difficulties. In particular, blood protein binding may affect the measure-

(a)
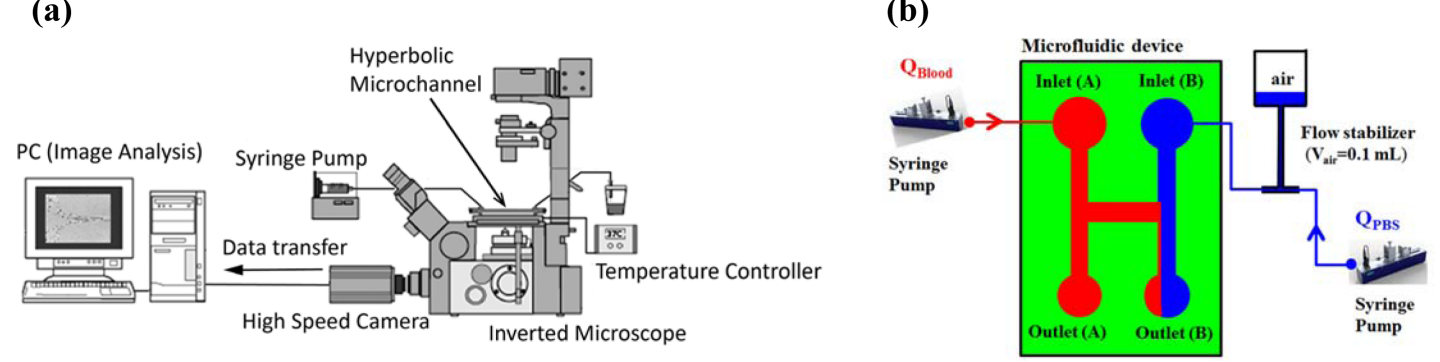

(d)
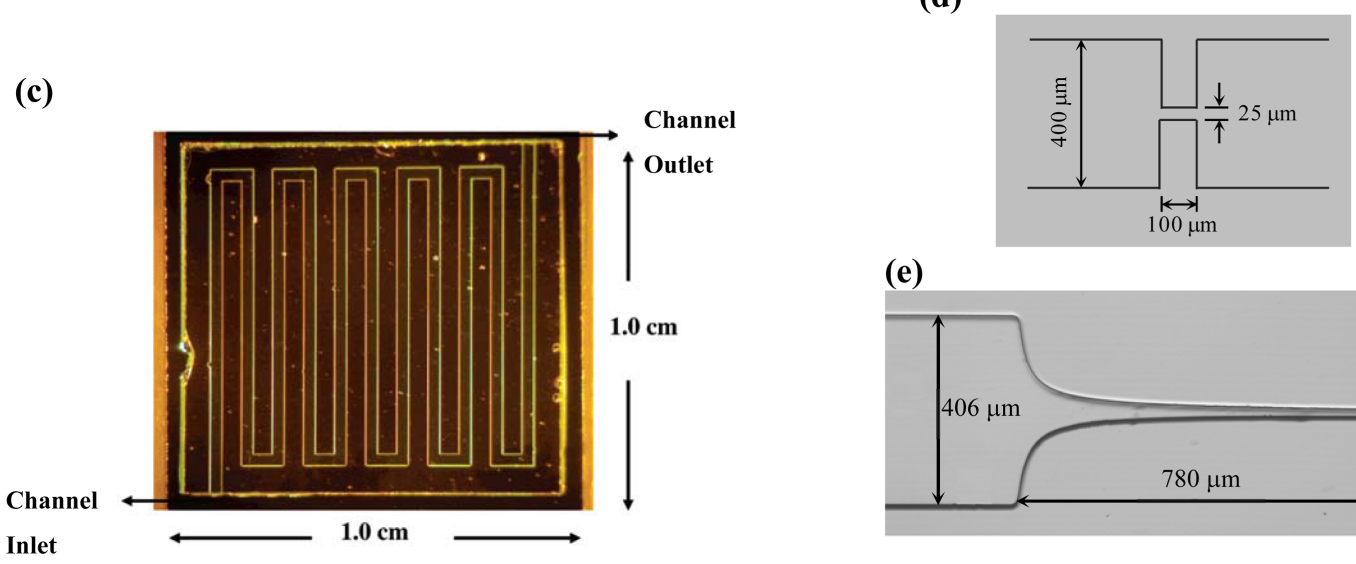

(e)

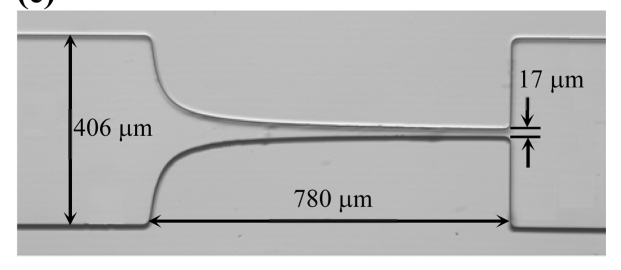

Fig. 5. (Color online) Microfluidic devices employed in blood rheological measurements. (a) The experimental set-up is typically composed of an inverted microscope on which the microfluidic chip is placed, a digital camera for recording images, a syringe pump for imposing a flow rate and a temperature controller for controlling the temperature of the fluid. Reprinted with permission from Yaginuma et al. (2013) (b) Microfluidic analogue of Wheatstone-bridge channel used by Kang and Lee (2013). Reprinted with permission from Kang and Lee (2013). Blood is fed to inlet A and a PBS solution to inlet B by means of syringe pumps. To ensure constant flow rates for both fluids, a flow stabilizer with $0.1 \mathrm{ml}$ cavity volume was placed between the syringe pump and the channel inlet of PBS solution. (c) Microfabricated viscometer used by Srivastava et al. (2005). The channel, $340 \mu \mathrm{m}$ wide and $36 \mu \mathrm{m}$ in depth, is etched in glass and bounded to silicon and open to the atmosphere on the inlet and outlet. Reprinted with permission from Srivastava et al. (2005). Copyright (2015) American Chemical Society. (d) Sketch of the microfluidic channel composed of an abrupt contraction followed by an abrupt expansion used by Brust et al. (2013). The depth of the channel is $50 \mu \mathrm{m}$. (e) Optical micrograph of the hyperbolic-shaped contraction followed by an abrupt expansion channel similar to that employed by Yaginuma et al. (2013). The depth of the channel is 60 $\mu \mathrm{m}$. The same type of contraction was also used in the work of Lee et al. (2009) for investigating RBC deformability. 
consequently produce small amounts of waste and can be combined with optical systems for visualization (Fig. 5a).

Microfluidic devices able to operate as blood viscometers have been developed in order to overcome the drawbacks of the macro-scale devices and are a promising tool for use in clinical practice because of their fast response and minimum fluid requirement. Such micro-devices have been used to measure the shear viscosity (Srivastava et al., 2005; Zeng and Zhao, 2009; Smith et al., 2010) and viscoelasticity (Brust et al., 2013; Kang and Lee, 2013) of blood. Microfluidic viscometers are based on a range of different principles as reviewed by Ong et al. (2010), such as capillary pressure-driven flow (Srivastava et al., 2005), electrical impedance spectroscopy (Zeng and Zhao, 2009), laser-induced capillary wave (Taguchi et al., 2009) and oscillating micro-structure induced by an electrostatic driving force (Smith et al., 2010). For instance, in the micro viscometer proposed by Srivastava et al. (2005), which is illustrated in Fig. 5c, the pressure drop over the channel length is used to determine the plasma viscosity. The device requires a sample volume of $600 \mathrm{nl}$ and is able to perform the measurement in less than $100 \mathrm{~s}$. However, microfluidic devices often require a syringe pump or, in some cases, a pressurized reservoir and connecting tubes to be combined with the microchip in order to promote the blood flow, which typically implies larger sample volumes. An exception is the micro-optical capillary sensor based on laser-induced capillary wave developed by Taguchi et al. (2009), in which the sample is placed directly on the sensor. Measurements using distilled water with a pigment have been performed for a proof-of-concept, but the device is yet to be tested with real blood. Two potential shortcomings of the method are the possible occurrence of sample evaporation and the micro-sensor being affected by surrounding vibrations. Due to the reduced measurement times required in these devices, it is expected that the addition of an anticoagulant to the blood sample is less critical, although it continues to be used in some works (Zeng and Zhao, 2009). Interestingly, the shear rates reported in these investigations are in the approximate range between 1 and $10^{3} \mathrm{~s}^{-1}$, which is similar to the reliable range of shear rates used in macro-scale apparatuses.

It is well known that an adequate temperature control in the measurement of rheological properties of blood is very important. Recently, a microfluidic viscometer that uses an array of microchannels equipped with a temperature controller was developed by Kang and Yang (2013). The temperature of the fluid within the channel was controlled using a Peltier system, micro-sized thermocouples and a feedback controller, which increases substantially the complexity of the microfabrication process. In addition, the micro-device requires the use of a reference fluid and the blood viscosity is measured by counting the number of indicating channels in the array which are filled with blood and with the reference fluid.

In terms of viscoelasticity, Kang and Lee (2013) proposed to measure a characteristic relaxation time of blood by controlling the transient blood flow in a microfluidic device analogue of a Wheatstone bridge (Fig. 5b). The microfluidic device consists of one channel connecting two side channels and the characteristic time of blood, an important parameter for evaluating blood viscoelasticity, is determined examining the area of the connecting channel that is filled with blood for a certain pressure drop between the side channels. The determination of the area of the channel filled with blood is based on image processing. This type of micro-device avoids the use of integrated sensors in the microchip and the need for calibration, although a reference fluid is required.

An interesting approach in microfluidics is taking advantage of the shape of the micro-channel to impose controllable deformations. Recently, the blood plasma viscoelasticity was assessed in a microchannel containing a contraction-expansion geometry (Fig. 5d) in order to promote a strong extensional flow (Brust et al., 2013). Measurements of the pressure drop in the channel revealed a nonlinear flow resistance with the increase of plasma flow rate, which is a typical behavior of a viscoelastic fluid.

In order to study the effects of extensional flow on RBC deformation, microchannels with a hyperbolic converging region (Fig. 5e) have been used due to the acceleration imposed by the converging section (Lee et al., 2009; Yaginuma et al., 2013). Such type of microfluidic devices that generate a strong extensional flow field are promising tools that can be applied in the detection and diagnosis of several diseases related to RBC deformability.

There are clear advantages of using microfluidics for measuring blood rheological properties as discussed above, but there are also some drawbacks that need to be considered, namely red blood cell clogging, measurement stability associated with weak signals and reproducibility. In addition, the formation of the cell-free layer is an added challenge in the rheological measurements at the microscale. Incidentally, Faivre et al. (2006) found that in a microchannel with an abrupt contraction followed by an abrupt expansion, the cellular content in the middle of the downstream channel increases $24 \%$ for a flow rate of $200 \mu \mathrm{l} / \mathrm{h}$ and an initial hematocrit of $16(\mathrm{v} / \mathrm{v}) \%$.

\subsubsection{Microrheology and other micro-scale techniques}

Microrheology techniques allow the measurements of the rheological properties of a complex fluid from the motion of colloidal probes directly embedded in the sample since the time-dependent trajectories of tracer particles dispersed in the fluid can be related to the linear viscoelastic properties of that fluid (Yao et al., 2009). These techniques, which can be divided into active and passive microrheology (cf. Table 1), are useful to perform in situ 
Patrícia C. Sousa, Fernando T. Pinho, Manuel A. Alves and Mónica S.N. Oliveira

Table 1. Microrheology and other micro-scale techniques used in the investigation of blood viscoelasticity.

\begin{tabular}{|c|c|c|c|c|c|c|}
\hline & Technique & Principle & Measurement & Advantages & Disadvantages & References \\
\hline \multirow{3}{*}{ 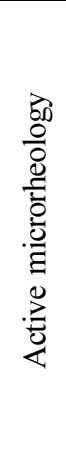 } & $\begin{array}{l}\text { Optical } \\
\text { tweezers }\end{array}$ & \multirow{3}{*}{$\begin{array}{l}\text { Applied } \\
\text { external } \\
- \text { forcing }\end{array}$} & \multirow{3}{*}{$\begin{array}{l}\text { Deformability/ } \\
\text { viscoelastic } \\
\text { character of } \\
\text { RBC }\end{array}$} & $\begin{array}{l}\text { Non-invasive; } \\
\text { Precise measure of } \mathrm{pN} \\
\text { forces }\end{array}$ & $\begin{array}{l}\text { Complex equipment } \\
\text { required; } \\
\text { Non-uniform deformation }\end{array}$ & $\begin{array}{l}\text { Dao et al. (2003); Lim et } \\
\text { al. (2004); Li et al. (2009); } \\
\text { Fontes et al. (2011) }\end{array}$ \\
\hline & $\begin{array}{l}\text { Magnetic } \\
\text { manipulation }\end{array}$ & & & $\begin{array}{l}\text { Non-invasive; } \\
\text { Selectivity of the magnetic } \\
\text { beads }\end{array}$ & $\begin{array}{l}\text { Difficult measurement; } \\
\text { Sensitivity }\end{array}$ & $\begin{array}{l}\text { Puig-De-Morales- } \\
\text { Marinkovic et al. (2007); } \\
\text { Li et al. (2014) }\end{array}$ \\
\hline & $\begin{array}{l}\text { Atomic force } \\
\text { microscopy }\end{array}$ & & & $\begin{array}{l}\text { Simple and rapid sample } \\
\text { preparation; } \\
\text { pN resolution; } \\
\text { Measurements under near- } \\
\text { physiological conditions }\end{array}$ & $\begin{array}{l}\text { Large size and high stiff- } \\
\text { ness of the cantilevers; } \\
\text { Possible interaction } \\
\text { between AFM tip and } \\
\text { molecule under study }\end{array}$ & Bremmell et al. (2006) \\
\hline 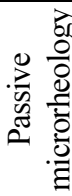 & & $\begin{array}{l}\text { Thermal } \\
\text { fluctuations }\end{array}$ & $\begin{array}{l}\text { Viscoelastic } \\
\text { moduli of } \\
\text { whole blood }\end{array}$ & $\begin{array}{l}\text { Linear viscoelastic regime } \\
\text { since there is no external } \\
\text { stress applied }\end{array}$ & $\begin{array}{l}\text { Requirements in the } \\
\text { probes selection; } \\
\text { Temperature control }\end{array}$ & Campo-Deaño et al. (2013) \\
\hline \multirow{4}{*}{ 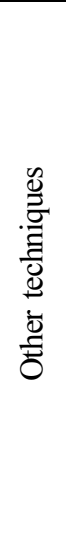 } & $\begin{array}{l}\text { Micropipette } \\
\text { aspiration }\end{array}$ & $\begin{array}{l}\text { Applied } \\
\text { negative } \\
\text { pressure }\end{array}$ & $\begin{array}{l}\text { Mechanical } \\
\text { properties of } \\
\text { RBC }\end{array}$ & $\begin{array}{l}\text { Simple technique; } \\
\text { For individual cells; } \\
\text { Precise measure of } \mathrm{pN} \text { forces }\end{array}$ & Time-consuming & Artmann et al. (1997) \\
\hline & Filtration & $\begin{array}{l}\text { Applied } \\
\text { negative } \\
\text { pressure }\end{array}$ & $\begin{array}{l}\text { Deformability } \\
\text { of } \mathrm{RBC}\end{array}$ & $\begin{array}{l}\text { Relatively simple } \\
\text { instruments; } \\
\text { High reproducibility }\end{array}$ & $\begin{array}{l}\text { Selectivity: feasible only } \\
\text { for reasonably deformable } \\
\text { cells; } \\
\text { Blockage of the pores }\end{array}$ & Koutsouris et al. (1988) \\
\hline & Rheoscopy & & & $\begin{array}{l}\text { Visualization; } \\
\text { For individual cells }\end{array}$ & $\begin{array}{l}\text { Complex design of the } \\
\text { equipment }\end{array}$ & Dobbe et al. (2004) \\
\hline & Ektacytometry & Shear flow & $\begin{array}{l}\text { Deformability } \\
\text { of } \mathrm{RBC}\end{array}$ & $\begin{array}{l}\text { Volume samples lower than } \\
50 \mu \mathrm{L} \text {; } \\
\text { Measurement in less than } \\
1 \text { min }\end{array}$ & Complex equipment & $\begin{array}{l}\text { Shin et al. (2007); Baskurt } \\
\text { et al. (2009b) }\end{array}$ \\
\hline
\end{tabular}

measurements and have also been used to assess the elastic character of blood. Contrarily to microfluidics, microrheology techniques typically do not require the use of accessories such as tubes and syringes for promoting the fluid flow and only require a volume sample of the order of $10 \mu \mathrm{l}$ to fill the sample chamber (Yao et al., 2009).

Active microrheology techniques involve the active manipulation of small probe particles using external applied forcings, whereas in passive microrheology techniques the tracer particles' motion is induced by thermal fluctuations (Squires and Mason, 2010). Active microrheology techniques typically use optical tweezers, magnetic manipulation techniques or atomic force microscopy (Neuman and Nagy, 2008).

Optical tweezers have been extensively used to investigate the mechanical (Dao et al., 2003; Lim et al., 2004; Li et al., 2009) and electrical properties of RBC (Fontes et al., 2011). In this non-invasive method, a highly focused beam of light, focused through a microscope objective, attracts and traps a high refractive index particle as sketched in Fig. 6a. Using optical tweezers it is possible to measure particle displacements of the order of nanometers with applied forces in the $\mathrm{pN}$ range (Yao et al., 2009). The technique requires a microscope and a high numerical aperture objective able to focus efficiently the laser beam. When a cell is attached to such a trapped particle, moving the focused laser beam forces the particle to move through the surrounding material, corresponding to the application of a local stress and the resultant displacement can be converted in terms of viscoelastic response using image analysis. The accuracy of the results depends on the precision of the image analysis technique, which is typically of the order of 1 pixel, but sub-pixel resolution can be achieved to measure the mechanical properties of RBC ( $\mathrm{Li}$ et al., 2009).

Similarly to optical tweezers, in magnetic twisting cytometry techniques spherical beads are attached to the cell cytoskeleton in order to generate stresses. A torque is applied to each bead, which causes the twist of the magnetic microparticle bounded to the membrane receptor and the resultant bead rotation is measured. Magnetic twisting cytometry generates a larger range of stresses than when 
(a)

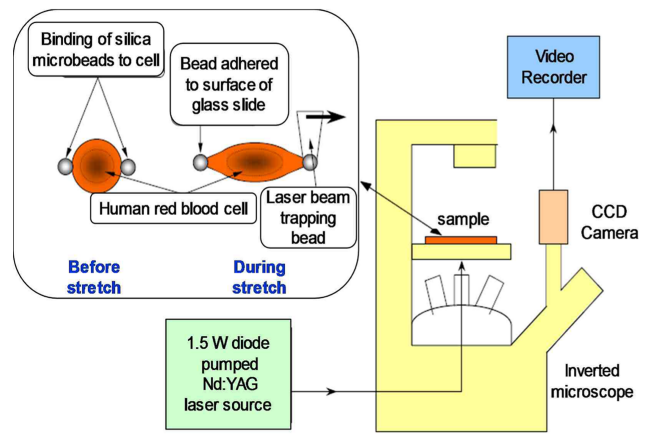

(c1)

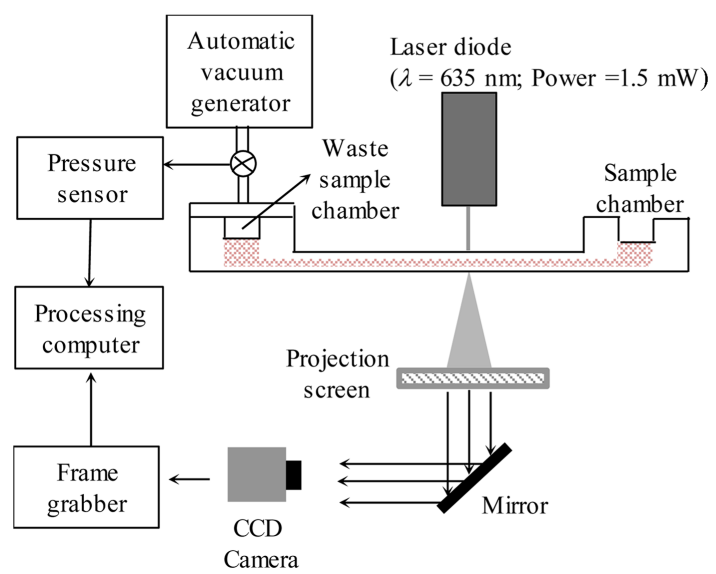

(b)

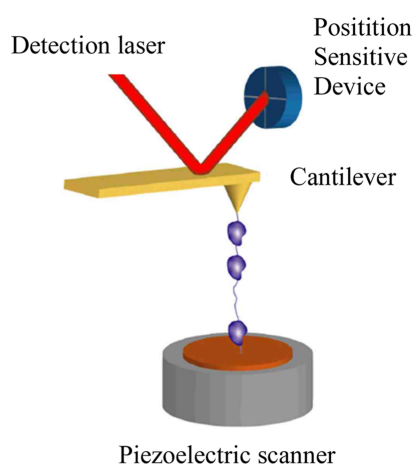

(c2)

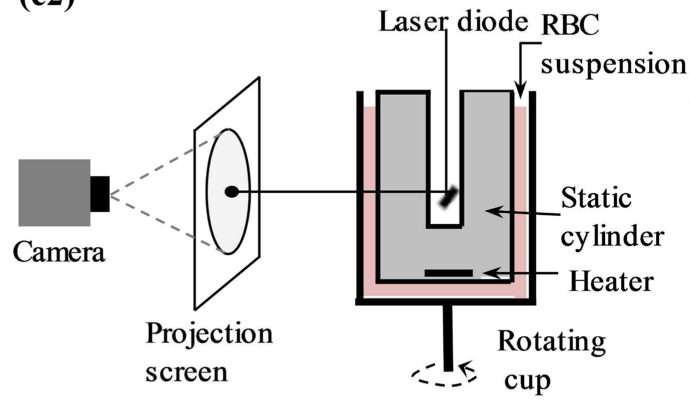

Fig. 6. (Color online) (a) Schematics of an optical tweezers set-up. Two microbeads are binded to the RBC at opposite points, one bead is anchored to the surface of a glass slide and the other can be trapped using the laser beam and the force is applied through the movement of the laser beam. Reprinted with permission from Dao et al. (2003). (b) Schematics of the AFM technique. The deflection of a pre-functionalized cantilever is measured by the displacement of a low power laser reflected on a Position Sensitive Device (PSD). The piezo stage is retracted along the axial direction and the stretching of the molecule is equal to the distance between the AFM tip and the sample surface. Reprinted with permission from Neuman and Nagy (2008). (c) Comparison between the RheoScan-D (c1) and LORCA (c2) systems. The RheoScan-D employs a channel $4 \mathrm{~mm}$ wide and $40 \mathrm{~mm}$ long with a depth of $200 \mu \mathrm{m}$ and analyses RBC deformability whereas the LORCA system can measure the aggregation and deformability of the RBC in a Couette cell.

relying on optical tweezers, in which a unidirectional force is applied to a single attached bead. The nature and magnitude of the applied stress in magnetic twisting torque cytometry and in optical tweezers may lead to differences in the results obtained using both techniques (Laurent et al., 2002). The storage modulus of RBC was investigated using optical magnetic twisting cytometry and its numerical analog, the twisting torque cytometry (Puig-De-Morales-Marinkovic et al., 2007; Li et al., 2014).

Valuable information concerning physical properties, as well as alterations in RBC, can be obtained using atomic force microscopy (AFM). This technique provides nanoscale topographic resolution and has been used to investigate the elastic properties of RBC (Bremmell et al., 2006). Micro-spheres are attached to a cantilever (Fig. 6b), which is used to scan the sample surface. In a force profile mode, the probe approaches the cell surface, contacts and then retracts. The force profile becomes nonlinear and reflects the mechanical properties of the cells (Neuman and Nagy, 2008). AFM allows measurements of inter- and intramolecular interaction forces with $\mathrm{pN}$ resolution. Recently, Steffen et al. (2013) measured the dextran-induced aggregation of RBC using atomic force microscopy-based single cell force spectroscopy. Different dextran molecules were used and the corresponding interaction energy between red blood cells was measured. The results obtained for the interaction energy can be described by the depletion theory, although a detailed investigation of the cause for stronger adhesion energies is still lacking.

Passive microrheology uses the Brownian motion of tracer particles to measure the rheology and structure of a material. The mean squared displacement (MSD) of the particles is measured and related to the viscosity of the 
material by the Stokes-Einstein equation, which is valid for Newtonian fluids. For a viscoelastic material, the generalized Stokes-Einstein relationship is used with the Newtonian viscosity replaced by the frequency-dependent complex viscosity of the material (Squires and Mason, 2010). Hence, the time-evolution of the MSD of tracers can be used to obtain the linear viscoelastic moduli of the sample. Campo-Deaño et al. (2013) employed passive microrheology techniques in order to measure the viscoelastic properties of whole blood by measuring the storage and loss moduli. These techniques require the use of a microscope and corresponding optical accessories. In addition, care must be taken when choosing the colloidal probes in order to ensure its sphericity, polydispersity and the absence of interactions between the particles and the medium (Breedveld and Pine, 2003). In this type of measurements the temperature may be difficult to control or it may be difficult to reach the physiological temperature, which is desirable for whole blood measurements. CampoDeaño et al. (2013) performed the measurements at $27^{\circ} \mathrm{C}$ and used the time-temperature superposition method, which is a common practice in polymeric samples when the range of temperatures is modest, to infer the viscoelastic moduli of human blood at $37^{\circ} \mathrm{C}$.

Micropipette aspiration techniques have been extensively used to measure the mechanical properties of RBC membranes. Here, a glass micropipette is used to apply a negative pressure onto the RBC membrane leading to the aspiration of the cell membrane into the pipette and progressive membrane deformation is measured as a function of time using optical microscopy. The internal diameter of the micropipette and the applied pressure can be selected to control the extent of the deformation. The elastic modulus, viscosity and characteristic time for relaxation of the cell membrane can be determined by matching the experimentally observed changes of the cell, namely the aspiration length, for a given pressure and configuration with analytical models (Dao et al., 2003). Micropipette aspiration is an advantageous technique for mechanical characterization of cells since it is simple, relatively inexpensive and can provide forces as low as $\mathrm{pN}$. Investigations of the human RBC membrane using this technique found an implied in-plane shear modulus of $4-10 \mathrm{mN} / \mathrm{m}$, a relaxation time of 0.10-0.13 $\mathrm{s}$ and a membrane viscosity of 0.6$2.7 \mu \mathrm{N} \cdot \mathrm{s} \cdot \mathrm{m}^{-1}$ (Lim et al., 2004). However, in micropipette aspiration, as well as in AFM and optical trap techniques, the deformation is nonuniform.

Other techniques have been used for measuring RBC deformability, such as filtration through pores of 3-5 $\mu \mathrm{m}$ in diameter with the transit time being determined during the measurement; rheoscopy; and ektacytometry (Shin et al., 2007). In rheoscopy, the cells are subject to simple shear flow in a rotating cone-plate system and a microscope is required for focusing the middle plane between the cone and the plate. In ektacytometry a laser beam is projected through a RBC suspension and the resulting diffraction pattern analyzed in order to determine the $\mathrm{RBC}$ shape and consequently deformability. A comparison between instruments commercially available for ektacytometry was performed by Baskurt et al. (2009b), using the LORCA (Laser assisted optical rotational cell analyzer, Mechatronics Instruments BV, Zwaag, The Netherlands), the Rheodyn SSD (Myrenne GmbH, Roetgen, Germany) and the RheoScan-D (RheoMeditech, Seoul, Korea) systems. The LORCA (Fig. 6c2) and the Rheodyn SSD systems cannot be strictly classified as micro-scale instruments given their characteristic dimensions; the RheoScan-D (Fig. 6c1) on the other hand combines microfluidics with laser-diffraction techniques. Shin et al. (2007) compared the deformability of $\mathrm{RBC}$ at various shear stresses measured using the RheoScan-D and the LORCA systems and the results obtained with both instrument were found to be in excellent agreement.

\section{Hemorheology}

Hemorheology deals with the flow and deformation behavior of blood and its formed elements (Popel and Johnson, 2005). The complex RBC aggregation and deformation hysteretic processes have been extensively investigated and found to be relevant in the context of hemorheology as discussed in the following sections. A list summarizing relevant investigations on blood shear rheology performed in the last two decades is presented in Table 2.

\subsection{Steady shear viscosity of blood}

The combined effects of aggregation and deformation of RBC impart a shear-thinning rheological behavior to blood as illustrated in Fig. 7 and are known to be closely linked to the presence of plasma proteins. In healthy human whole blood, RBC form aggregates at low shear rates and as a consequence blood resistance to flow is increased with whole blood shear viscosity being about one hundred times higher than that of water. Increasing the shear rate disrupts the aggregate structures above a critical shear rate, leading to shear-thinning behavior, as shown in Fig. 7. An initial lower degree of aggregation of $\mathrm{RBC}$ involves weaker attractive forces between the cells, causing a lower critical shear rate at which disaggregation of the RBC occurs (Thurston, 1979). As RBC are dispersed, deformed and aligned with flow direction due to higher flow velocities (shear rates), the shear viscosity decreases substantially by approximately two orders of magnitude, as shown in Fig. 7 and its value at high shear rates is about three times the shear viscosity of water.

The aggregation of normal RBC taking place at low shear rates leads to a higher apparent viscosity than when 
Table 2. Review of blood shear-rheology studies using different measuring systems.

\begin{tabular}{|c|c|c|c|c|c|c|c|c|}
\hline \multirow{2}{*}{ Reference } & \multirow{2}{*}{$\begin{array}{c}T \\
\left({ }^{\circ} \mathrm{C}\right)\end{array}$} & \multirow{2}{*}{$\begin{array}{l}\text { Measuring system/ } \\
\text { method }\end{array}$} & \multicolumn{2}{|c|}{ Type of measurement } & \multirow{2}{*}{$\begin{array}{l}H c t \\
(\%)\end{array}$} & \multirow{2}{*}{ Blood sample } & \multirow{2}{*}{$\begin{array}{c}\text { Blood preparation/ } \\
\text { Anticoagulant }\end{array}$} & \multirow{2}{*}{ Remarks } \\
\hline & & & Steady & Oscillatory & & & & \\
\hline $\begin{array}{l}\text { Vlastos et al. } \\
\text { (1997) }\end{array}$ & 25 & Couette viscometer & $0.01 \leq \dot{\gamma} / \mathrm{s}^{-1} \leq 100$ & $\begin{array}{c}0.05 \leq \gamma_{0} \leq 13.11 \\
f=0.5 \mathrm{~Hz} \\
0.03 \leq f / \mathrm{Hz} \leq 5 \\
\gamma_{0}=0.2\end{array}$ & 45 & $\begin{array}{l}\text { - Autologous } \\
\text { plasma + RBC }\end{array}$ & Heparin & $\begin{array}{l}\text { - Steady and oscillatory shear tests combined } \\
\text { in the same measurement } \\
\text { - Blood viscoelasticity decreases when a } \\
\text { steady shear rate is superimposed }\end{array}$ \\
\hline $\begin{array}{l}\text { Kim et al. } \\
(2000)\end{array}$ & 37 & $\begin{array}{l}\text { Scanning viscometer } \\
\text { with capillary tube }\end{array}$ & $30 \leq \dot{\gamma} / \mathrm{s}^{-1} \leq 375$ & - & $\begin{array}{c}40.5 \\
41 \\
46.5 \\
\end{array}$ & - Whole blood & No anticoagulant & $\begin{array}{l}\text { - Measurement performed in } 2 \mathrm{~min} \\
\text { - Blood volume sample of } 5 \mathrm{ml}\end{array}$ \\
\hline $\begin{array}{l}\text { Shin et al. } \\
\text { (2004) }\end{array}$ & 25 & $\begin{array}{l}\text { Pressure-scanning } \\
\text { viscometer }\end{array}$ & $1 \leq \dot{\gamma} / \mathrm{s}^{-1} \leq 1000$ & - & n. m. & $\begin{array}{l}\text { - Whole human } \\
\text { blood }\end{array}$ & n. m. & $\begin{array}{l}\text { - Measurement of the pressure variation with } \\
\text { time in a collecting chamber } \\
\text { - Comparison between new method and a } \\
\text { rotating viscometer }\end{array}$ \\
\hline $\begin{array}{l}\text { Alexy et al. } \\
(2005 b)\end{array}$ & 37 & $\begin{array}{l}\text { Computerized scanning } \\
\text { capillary viscometer }\end{array}$ & $1 \leq \dot{\gamma} / \mathrm{s}^{-1} \leq 1500$ & - & $28-56$ & $\begin{array}{l}\text { - Whole blood } \\
\text { - RBC in plasma }\end{array}$ & EDTA & $\begin{array}{l}\text { - Comparison between: new method and a } \\
\text { cone-plate; new method and Couette }\end{array}$ \\
\hline $\begin{array}{l}\text { Mark et al. } \\
(2006)\end{array}$ & 37 & $\begin{array}{l}\text { Oscillating resonator } \\
\text { probe }\end{array}$ & - & $\checkmark$ & $20-60$ & $\begin{array}{l}\text { - RBC in Dextran } \\
40 \\
- \text { RBC in Dextran } \\
70\end{array}$ & EDTA & $\begin{array}{l}\text { - Measurement system into the vacutainer } \\
\text { tube for blood withdrawal } \\
\text { - Comparison between new method and Cou- } \\
\text { ette system }\end{array}$ \\
\hline $\begin{array}{l}\text { Eugster et al. } \\
(2007)\end{array}$ & 37 & $\begin{array}{l}\text { Oscillating torsional } \\
\text { resonator viscometer }\end{array}$ & - & $\checkmark$ & $20-60$ & - Whole blood & EDTA & - Couette viscometer for comparison purposes \\
\hline $\begin{array}{l}\text { Eguchi and } \\
\text { Karino } \\
(2008)\end{array}$ & 37 & Falling ball viscometer & $\checkmark$ & - & $20-60$ & $\begin{array}{l}\text { - Whole blood } \\
\text { - RBC in serum } \\
\text { - RBC in Tyrode's- } \\
\text { albumin solution }\end{array}$ & Sodium citrate & $\begin{array}{l}\text { - Cone-plate viscometer for comparison pur- } \\
\text { poses }\end{array}$ \\
\hline $\begin{array}{l}\text { Travagli et al. } \\
\text { (2008) }\end{array}$ & 37 & $\begin{array}{l}\text { Oscillating torsional } \\
\text { viscometer }\end{array}$ & - & $\checkmark$ & $0-100$ & $\begin{array}{l}\text { - Whole blood } \\
\text { - RBC in plasma }\end{array}$ & EDTA & $\begin{array}{l}\text { - Rheometer with cone-plate geometry for } \\
\text { comparison purposes }\end{array}$ \\
\hline $\begin{array}{l}\text { Muramoto } \\
\text { and Nagasaka } \\
(2011)\end{array}$ & 37 & $\begin{array}{l}\text { Laser-induced capillary } \\
\text { wave viscometer }\end{array}$ & - & $\begin{array}{c}\checkmark \\
\text { (capillary wave) }\end{array}$ & $\begin{array}{l}39.2 \\
44.6\end{array}$ & - Whole blood & Heparin & $\begin{array}{l}\text { - Volume sample of } 90 \mu \mathrm{l} \\
\text { - Blood considered as Newtonian fluid }\end{array}$ \\
\hline $\begin{array}{l}\text { Campo- } \\
\text { Deaño et al. } \\
(2013)\end{array}$ & 27 & Passive microrheology & - & $\begin{array}{c}\checkmark \\
3 \leq \omega / \mathrm{rad} \mathrm{s}^{-1} \leq 600\end{array}$ & 44 & - Whole blood & EDTA & $\begin{array}{l}\text { - Viscoelasticity quantified in terms of } G^{\prime} \text { and } \\
G^{\prime \prime}\end{array}$ \\
\hline $\begin{array}{l}\text { Sousa et al. } \\
(2013)\end{array}$ & 37 & $\begin{array}{l}\text { Rotational rheometer } \\
\text { Plate-plate (rough sur- } \\
\text { face) }\end{array}$ & $1 \leq \dot{\gamma} / \mathrm{s}^{-1} \leq 350$ & $\begin{array}{c}\checkmark \\
(\mathrm{LAOS})\end{array}$ & $\begin{array}{l}41.3 \\
41.6\end{array}$ & - Whole blood & EDTA & $\begin{array}{l}\text { - Anticoagulant has no influence on rheolog- } \\
\text { ical results } \\
\text { - Viscoelastic behavior found with the viscous } \\
\text { character more marked than the elastic one }\end{array}$ \\
\hline
\end{tabular}

[Legend] n.m.: not mentioned, $\dot{\gamma}\left(\mathrm{s}^{-1}\right)$ : shear rate, $f(\mathrm{~Hz})$ : frequency, $\gamma_{0}(-)$ : strain amplitude, $G^{\prime}(\mathrm{Pa})$ : storage modulus, $G^{\prime \prime}(\mathrm{Pa})$ : loss modulus, $\omega\left(\mathrm{rad} \mathrm{s}^{-1}\right)$ : angular frequency 
Patrícia C. Sousa, Fernando T. Pinho, Manuel A. Alves and Mónica S.N. Oliveira

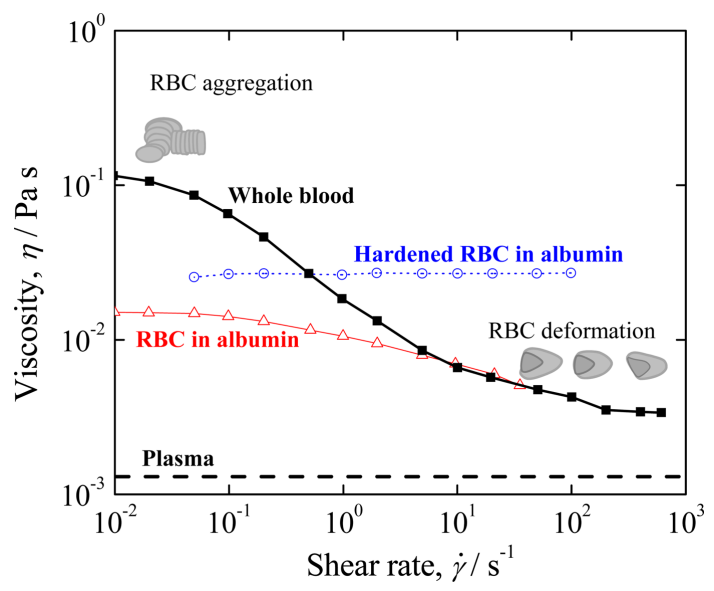

Fig. 7. (Color online) Shear viscosity of blood as a function of shear rate for normal human blood, normal red blood cells in $11 \%$ albumin-Ringer solution and red blood cells hardened by glutaraldehyde in $11 \%$ albumin-Ringer solution. All suspensions contain $45(\mathrm{v} / \mathrm{v}) \%$ of RBC. The plasma and the suspension of rigid erythrocytes in plasma show a Newtonian rheological behavior in shear, whereas RBC aggregation and deformation lead to a shear-thinning shear viscosity. The differences in the curves highlight the effects of RBC aggregation and deformation. Adapted from Chien (1970).

$\mathrm{RBC}$ are suspended in a non-aggregating medium such as $11(\mathrm{v} / \mathrm{v}) \%$ albumin-Ringer solution in plasma (Chien, 1970). The differences between the flow curves for normal blood and for a suspension of RBC in the albumin-Ringer solution shown in Fig. 7 demonstrate the impact of cell aggregation on the shear-thinning properties at low shear rates. Fig. 7 also shows that when erythrocytes harden, as occurs in some diseases, the shear-thinning behavior is weakened or even lost due to the lower capability of the hardened $\mathrm{RBC}$ to deform under shear and to form aggregates.

During a cardiac cycle the flow is pulsatile, with pressure and flow velocity varying in time and space in the vascular network. Consequently, as a shear rate dependent property, whole blood viscosity also changes in time and location. At low velocities, the apparent viscosity of blood increases in bulk shear flow due to the reduced deformation of RBC with decreasing levels of shear stress/rate and the tendency of RBC to aggregate (Pozrikidis, 2003).

Fig. 8 compares blood viscosity measurements by different authors under steady shear. Fig. $8 \mathrm{a}$ includes data at different hematocrit levels, ranging from $41.2 \%$ to $51.7 \%$, measured at the physiological temperature $\left(37^{\circ} \mathrm{C}\right)$ using different methodologies, whereas Fig. 8b shows an overview of different flow curves measured at a range of lower temperatures $\left(T=4^{\circ} \mathrm{C}\right.$ to $\left.37^{\circ} \mathrm{C}\right)$ but over a narrower range of hematocrit values, from $41.3 \%$ to $46 \%$. Due to the diversity of conditions used in different investigations, namely the hematocrit levels, temperature of measurement, range of shear rates, or the blood sample preparation

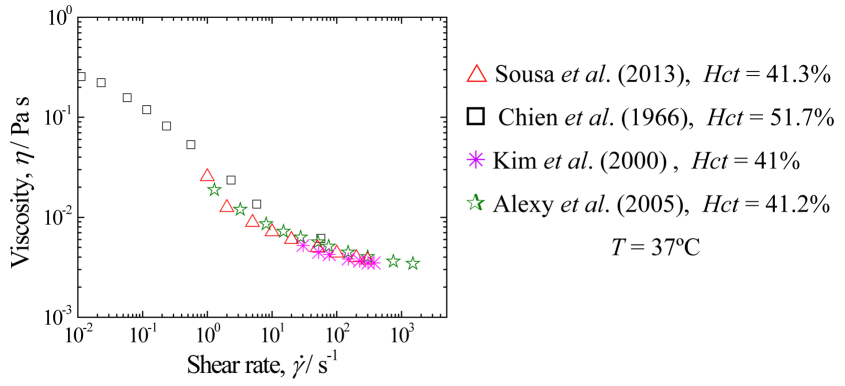

(a)

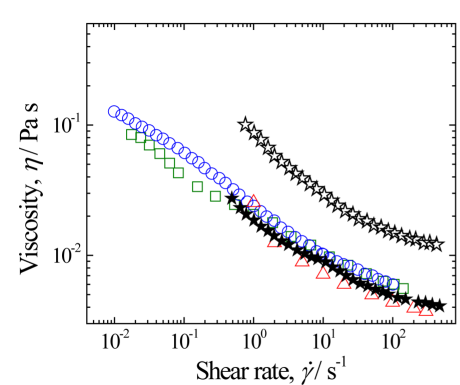

(b)

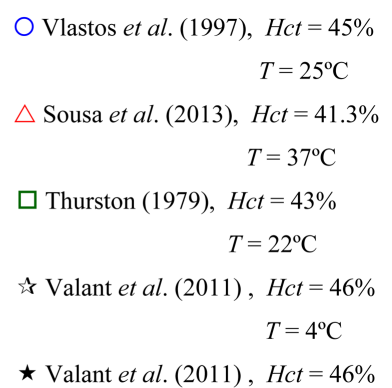

$T=37^{\circ} \mathrm{C}$
Fig. 8. (Color online) Viscosity of human blood as a function of shear rate obtained experimentally in different works. (a) $T=$ $37^{\circ} \mathrm{C}$; (b) $T=4-37^{\circ} \mathrm{C}$. Blood viscosity data obtained by Alexy et al. (2005b) was measured from 44 donors at a mean hematocrit of $41.2 \%$ using an automated scanning capillary viscometer (Rheolog ${ }^{\mathrm{TM}}$ ). Chien et al. (1966) employed a coaxial cylinder viscometer; Kim et al. (2000) used a scanning capillary tube viscometer; Sousa et al. (2013) and Valant et al. (2011) used a shear rheometer (Physica MCR301, Anton Paar) with a serrated plateplate geometry and a double gap cell, respectively; Thurston (1979) and Vlastos et al. (1997) employed a Couette-type viscometer, Contraves LS 30 and Contraves LS 40, respectively.

method, it is difficult to make a direct comparison between them. Nevertheless, the shear-thinning behavior of blood viscosity is clear and in spite of the differences in the values of the Hct, the viscosity data obtained by different authors agrees well, particularly at high shear rates, as shown in Fig. 8a. It is important to note that the data presented in Fig. 8 was obtained with human blood samples. Care must be taken when comparing data obtained using animal blood due to the large variation in size, heart rate, life style between animals as reviewed by Rampling (2007). For instance, Johnn et al. (1992) found that the blood viscosity of 31 mammals investigated may vary by some 2-fold at high shear rates and 18-fold at low shear rates due to the variation in $H c t$ and plasma viscosity.

Blood viscosity is affected by the variability of the characteristics inherent to the blood donor as well as by the following important parameters:

Hematocrit: It is well documented that blood steady shear viscosity increases exponentially with the hematocrit, as illustrated in Fig. 9, and that the variation of the 
viscosity is more pronounced at lower than at higher shear rates attesting the effect of the hematocrit on the values of the viscosity and on the shear-thinning behavior (Cokelet and Meiselman, 2007).

Temperature: The normal body temperature, also known as euthermia or normothermia, is approximately $37^{\circ} \mathrm{C}$, but lower temperatures are also important in various medical procedures such as surgery and it is thus of significant importance to understand the influence of temperature on the rheological properties of blood.

Many rheological measurements using human blood were conducted at low temperatures and therefore significant differences in steady shear rheology are observed (cf. Figs. 8a and 8b). The dependence of the viscosity on temperature in a narrow range can be described mathematically using an Arrhenius type equation, known as Andrade's equation (Barnes, 2000). Thurston (1996) measured the plasma viscosity as well as the viscous and elastic components of the complex viscosity under oscillatory flow conditions by applying a constant frequency of $2 \mathrm{~Hz}$ and a strain of 1 for temperatures ranging from $9^{\circ} \mathrm{C}$ to $42^{\circ} \mathrm{C}$. The equations found by Thurston, valid only for the conditions described above, are summarized in Table 3.

The effect of temperature on $\mathrm{RBC}$ aggregation and deformability and consequently on rheological properties of blood is also important. In fact, temperature plays a significant role in terms of cell function and dynamics. As discussed previously, blood viscosity increases with a decrease of temperature, while the aggregation index of RBC decreases when temperature is decreased (Lim et al., 2010). This can be explained by the fact that plasma viscosity increases when the temperature decreases and the rate of formation of RBC aggregates is delayed, with plasma being considered as an attenuating medium for RBC suspensions.

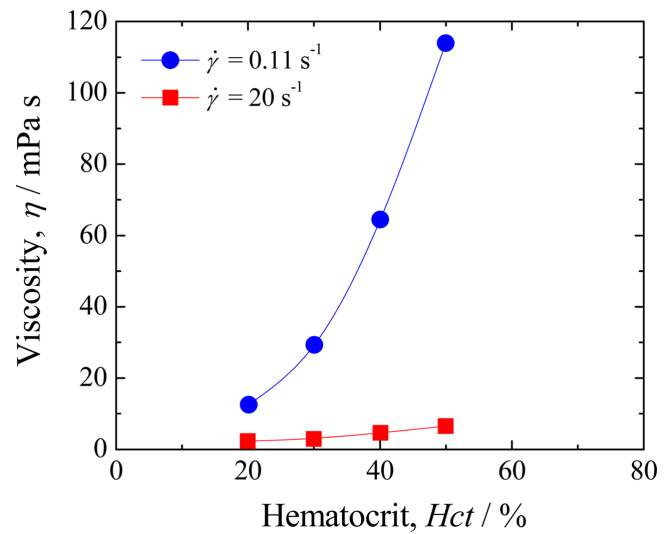

Fig. 9. (Color online) Effect of hematocrit on the viscosity for normal human RBC suspended in autologous plasma at two different values of shear rate. Adapted from Cokelet and Meiselman (2007).
Table 3. Summary of the equations describing the variation of the plasma viscosity and of the viscous and elastic components of the complex viscosity with temperature obtained by Thurston (1996) in the range $9<T\left[{ }^{\circ} \mathrm{C}\right]<42$.

\begin{tabular}{cc}
\hline \hline Plasma & Blood $(H c t=47 \%)$ \\
\hline$\eta_{\text {plasma }}[\mathrm{mPa} \cdot \mathrm{s}]=$ & $\eta^{\prime}[\mathrm{mPa} \cdot \mathrm{s}]=21.47 \times 10^{-0.01264 T\left[^{\circ} \mathrm{C}\right]}$ \\
$3.362 \times 10^{-0.01017 T\left[^{\circ} \mathrm{C}\right]}$ & $\eta^{\prime \prime}[\mathrm{mPa} \cdot \mathrm{s}]=4.213 \times 10^{-0.01022 T\left[^{\circ} \mathrm{C}\right]}$ \\
\hline
\end{tabular}

In addition, temperature also plays an important role in the deformability of intact (Artmann et al., 1998) and pathologic (Mills et al., 2007) red blood cells. Artmann et al. (1998) found that intact human RBC experience the passage through a $1.3 \mu \mathrm{m}$ micropipette only in the narrow range of temperatures of $36.4 \pm 0.3^{\circ} \mathrm{C}$ due to the elastomeric fluid/gel-like transition of hemoglobin. Furthermore, the deformability of pathologic RBC harboring Plasmodium falciparum is significantly reduced at febrile temperatures $\left(41^{\circ} \mathrm{C}\right)$ compared with normal physiological temperature (Mills et al., 2007).

Anticoagulant: The addition of anticoagulants for carrying out blood measurements, which delays the blood coagulation and consequently allows for longer measurement times, has been argued to change blood rheological properties when inadequate concentrations are used. Sousa et al. (2013) showed recently that the use of ethylenediaminetetraacetic acid (EDTA) at the maximum concentration $(1.8 \mathrm{mg} / \mathrm{ml})$ recommended by the International Society for Clinical Hemorheology (Baskurt et al., 2009a) has no significant influence upon the whole blood shear viscosity but care must be taken regarding the type and amount of anticoagulant added to the blood sample.

The shear-thinning behavior is frequently modelled using a Generalized Newtonian fluid (GNF) model with the blood shear-thinning viscosity described by simple equations, such as: Ostwald-de Waele power law model, Carreau model, Carreau-Yasuda model, Casson model, and Herschel-Bulkley model, see Table 4. These models can describe accurately the shear-thinning behavior but are not able to account for elasticity.

There are other more complex models that consider the viscoelastic characteristics of blood. For example, CampoDeaño et al. (2013) reported the fit to the shear viscosity as well as the viscoelastic moduli of whole blood using two commonly used viscoelastic multi-mode models, namely the simplified Phan-Thien-Tanner (sPTT) and the Giesekus models, while Owens (2006) proposed a new and more complex model that describes the viscoelastic behavior of blood. However, these more complex models that account for viscoelasticity are not used as often precisely due to the increased complexity. For a more complete description of blood rheology models the reader is 
Table 4. Non-Newtonian fluid models commonly used to describe blood shear viscosity. Note that the shear stress and shear rate are related as $\tau=\eta \dot{\gamma}$.

\begin{tabular}{cc}
\hline \hline Model & Equation \\
\hline Power Law & $\eta=k \dot{\gamma}^{n-1}$ \\
Carreau-Yasuda & $\eta=\eta_{\infty}+\frac{\eta_{0}-\eta_{\infty}}{\left[1+(\Lambda \dot{\gamma})^{a}\right]^{(1-n) / a}}$
\end{tabular}

(The Carreau model is obtained using $a=2$ )

\begin{tabular}{rlrl} 
Cross & $\frac{\eta-\eta_{\infty}}{\eta_{0}-\eta_{\infty}}$ & $=\frac{1}{1+(\Lambda \dot{\gamma})^{m}}$ \\
Casson & $\sqrt{\tau}=\sqrt{\tau_{0}}+\sqrt{k \dot{\gamma}}$ \\
Herschel-Bulkley & $\tau$ & $=\tau_{0}+k \dot{\gamma}^{n}$ \\
\hline
\end{tabular}

[Legend] $\eta$ : shear viscosity, $\eta_{0}$ : zero-shear rate viscosity, $\eta_{\infty}$ : high-shear rate viscosity, $k$ : consistency index, $n$ : power law index, $\Lambda$ : time constant, $m$ and $a$ : dimensionless parameters, $\tau$ : shear stress, $\tau_{0}$ : yield stress

referred to the reviews by Yilmaz and Gundogdu (2008) and Campo-Deaño et al. (2015), who report on more complex constitutive equations as well as on the parameters of the models that better fit experimental data.

\subsection{Blood thixotropy and yield stress}

Thixotropy is the reduction of viscosity with time in a fluid sample subjected to a constant shear rate (Barnes, 2000), an effect which occurs due to shear-induced changes in the fluid microstructure. Another manifestation of thixotropy is the hysteresis found in fluid properties, such as the viscosity and shear stress, in a cycle of increase and subsequent decrease in the imposed shear rate, as shown in Fig. 10. In the context of blood rheology, thixotropy has been reported to occur (Dintenfass, 1985) and has been linked to the aggregation and disruption dynamics of the RBC structures, in particular with the behavior and evolution of the rouleaux depending on the intensity and dura- tion of the applied stresses. An increase and subsequent decrease of shear rate results in lower apparent viscosities than initially at the same shear rates, since RBC structures are only formed at low shear rates and require some time to form, leading to hysteretic behavior in the apparent shear viscosity. It is also important to notice that cell sedimentation is faster with aggregates than with isolated $\mathrm{RBC}$, and undue consideration of their effect may lead to a misrepresentation of the thixotropic rheology of blood.

Time-dependent changes of rheological properties of blood are of great importance to describe the physiological conditions in the circulation, where blood experiences rapid and cyclic changes from low to high shear flow conditions during the cardiac cycle. It is important to note that larger vessels are those closer to the heart, where the timedependent effects are stronger on account of the proximity to the time-dependent stimulus.

Some materials are characterized by a critical yield stress, which must be exceeded for the material to flow. In a flow curve measured under steady shear flow, the yield stress can be defined as the limiting shear stress when the shear rate approaches zero (cf. Fig. 10b). The measurement of the blood yield stress is useful for the diagnostic of pathological conditions such as polycythemia (Merrill, 1969), systemic sclerosis (Picart et al., 1999) or diabetes (Radtke et al., 1984) since for such diseases the values of the blood yield stress are higher than in healthy conditions. When blood is at rest, attractive forces between cells arise, such as van der Waals forces, Coulombic forces (Cheng and Evans, 1965) and ion bridges or hydrogen bonds (Cho and Cho, 2011). Consequently, a critical pressure gradient is required to overcome the yield stress and promote blood flow. Early studies established that the yield stress of blood is independent of temperature in the range between $10^{\circ} \mathrm{C}$ and $37^{\circ} \mathrm{C}$ (Barbee, 1973). Subsequent investigations determined the blood yield stress indirectly by fitting the experimental shear stress-shear rate data to generalized Newtonian models (such as the Casson model represented

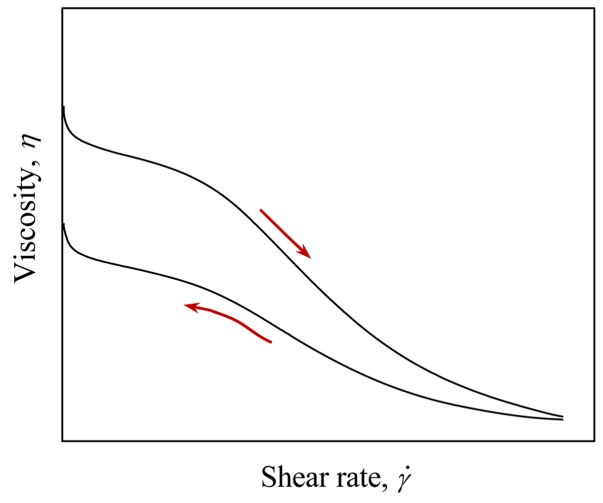

(a)

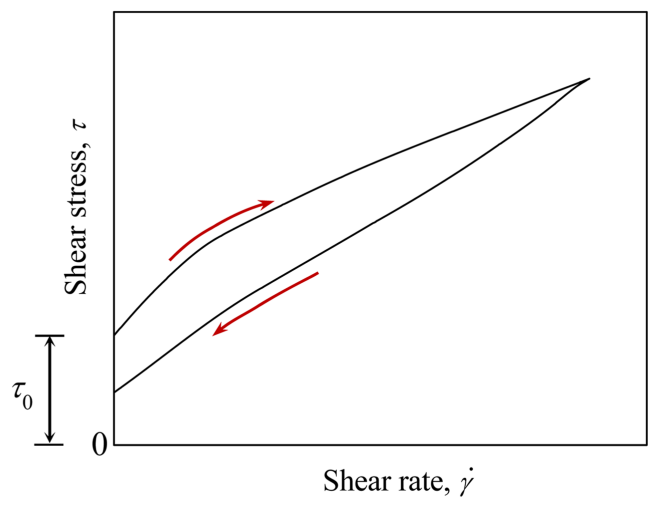

(b)

Fig. 10. (Color online) Typical thixotropic hysteresis loop observed in the curve of the shear viscosity as a function of shear rate (a) and in the curve of shear stress as a function of shear rate (b). The fluid yield stress $\left(\tau_{0}\right)$ is also illustrated in (b). 
Table 5. Summary of studies on whole blood yield stress $\left(\tau_{0}\right)$ : proposed correlations as function of hematocrit level (Hct) and temperature of measurement $\left(T_{\text {meas }}\right)$ (note: 1 dyne $\mathrm{cm}^{-2}=100 \mathrm{mPa}$ ).

\begin{tabular}{|c|c|c|}
\hline Reference & Correlations for yield stress & Parameters \\
\hline \multirow{2}{*}{ Merrill et al. (1963) } & $\tau_{0}\left[\right.$ dyne $\left.\mathrm{cm}^{-2}\right]=\tau_{y 0}\left(H c t-H c t_{c}\right)^{3}$ & $\begin{array}{l}30 \leq H c t / \% \leq 50 \\
\tau_{y 0} \approx 0.008 \text { dyne } \mathrm{cm}^{-2} \\
1.3 \leq H c t_{c} \text { (critical hematocrit) } / \% \leq 6.5\end{array}$ \\
\hline & $\tau_{0}\left[\right.$ dyne $\left.\mathrm{cm}^{-2}\right]=a e^{b H c t}$ & $\begin{array}{l}\text { Hct }>50 \% \\
a, b-\text { empirical constants } \\
10 \leq T_{\text {meas }} /{ }^{\circ} \mathrm{C} \leq 37\end{array}$ \\
\hline \multirow[t]{2}{*}{ Chien et al. (1966) } & $\tau_{0}\left[\right.$ dyne $\left.\mathrm{cm}^{-2}\right]=[a(H c t-b)]^{3}$ & $\begin{array}{l}\text { Hct }<80 \% \\
a=0.007 \mathrm{dyne}^{1 / 3} \mathrm{~cm}^{-2 / 3} \\
b=3.2 \%\end{array}$ \\
\hline & $\tau_{0}\left[\right.$ dyne $\left.\mathrm{cm}^{-2}\right]=e^{(a H c t+b)}$ & $\begin{array}{l}\text { Hct }>80 \% \\
a=0.058 \\
b=6.36 \% \\
T_{\text {meas }}=37^{\circ} \mathrm{C}\end{array}$ \\
\hline Zydney et al. (1991) & $\tau_{0}\left[\right.$ dyne $\left.\mathrm{cm}^{-2}\right]=\tau_{y 0}(H c t-0.05)^{3}$ & $\begin{array}{l}\tau_{y 0}=0.71 \text { dyne } \mathrm{cm}^{-2} \\
T_{\text {meas }}=37^{\circ} \mathrm{C}\end{array}$ \\
\hline Picart et al. (1998) & $\tau_{0}[\mathrm{mPa}]=\tau_{y 0} H c t^{3}$ & $\begin{array}{l}0.53 \leq H c t \leq 0.95 \\
\tau_{y 0}=26.87 \mathrm{mPa} \\
T_{\text {meas }}=25^{\circ} \mathrm{C}\end{array}$ \\
\hline
\end{tabular}

in Table 4) that incorporate a yield stress. Correlations reported by different authors for fitting blood yield stress as a function of hematocrit level are presented in Table 5. In spite of the efforts to determine the yield stress of blood, the results show considerable scatter since it is highly influenced by the hematocrit level, fibrinogen and RBC deformability. Moreover, the different experimental methods used and the complexity of blood contribute to the inconsistency between the values measured by different authors. In any case, it is clear that the blood yield stress is very low, of the order of $10^{-3} \mathrm{~Pa}$ for Hct in the range of 40-50\% (Picart et al., 1998; Lee et al., 2011a). Recently, it was found that yield stress is an onset phenomenon, which only occurs when the hematocrit exceeds a critical value, which in turn depends on the fibrinogen concentration (Apostolidis and Beris, 2014).

\subsection{Blood viscoelasticity}

The viscoelasticity of blood is associated with its twophase nature as well as with the morphological and elastic properties of the discrete phases, namely the RBC. Complex viscoelastic properties of RBC were reported by PuigDe-Morales-Marinkovic et al. (2007) and Li et al. (2014) when membrane rheology was investigated experimental and numerically using optical magnetic twisting torque cytometry or twisting torque cytometry, respectively. The interactions between the lipid bilayer and the cytoskeleton play an important role in the viscoelastic properties of RBC membrane and allow the cells to flow through capillaries of small diameter ( $\mathrm{Li}$ et al., 2014). As a consequence, it comes as no surprise that the elastic behavior of blood generally increases with hematocrit level due to increasing cell interactions. For shear rates ranging from 1 $\mathrm{s}^{-1}$ to $10 \mathrm{~s}^{-1}$ the viscous component of the complex viscosity increases exponentially with hematocrit whereas its elastic component increases nearly proportionally to the cube of the hematocrit. For shear rates above $10 \mathrm{~s}^{-1}$, both viscous and elastic components of the complex viscosity increase exponentially with hematocrit (Thurston, 1996).

Measurements of blood viscoelasticity have focused mostly on shear flow experiments including SAOS (Thurston 1972; 1996; Thurston and Henderson, 2007) and, only more recently, LAOS (Sousa et al., 2013) and passive microrheology (Campo-Deaño et al., 2013). Recent studies have also recognized the importance of the rheological behavior of plasma and blood under extensional flow (Brust et al., 2013).

\subsubsection{Small amplitude oscillatory shear (SAOS)}

SAOS tests are commonly used to characterize the frequency dependence of the rheological behavior of a material. Considering a fixed oscillatory maximum strain, the viscous and elastic components of the blood complex viscosity decrease moderately with an increase of the frequency of oscillation (Thurston, 1996) as shown in the inset of Fig. 11. Varying parameters such as hematocrit level or the RBC characteristics, namely deformability and aggregation, lead to modifications of the viscoelastic properties of blood as reviewed by Thurston and Henderson (2007).

Since blood viscoelasticity has a significant impact on blood flow, in particular on the propagation of the pressure 
pulse generated by the heart in the arterial system (Thurston and Henderson, 2007), most of the works do not focus only on these fundamental measurements alone, but combine them with other rheological tests to create more realistic kinematic flow conditions as discussed in the following sections.

Most of the measurements, and in particular those discussed in relation to Fig. 11, were carried out at flow conditions mimicking real pulsatile flow, with oscillatory flow superimposed onto a steady flow (Thurston 1979; 1996; Thurston and Henderson 2007). Thurston (1979) measured the viscous and elastic components of the complex viscosity under oscillatory flow conditions by applying a constant frequency $(f=2 \mathrm{~Hz})$ and varying the deformation applied to the sample. Additionally, a frequency sweep at constant strain amplitude was also performed. At low shear rates, viscoelasticity is dominated by the aggregation characteristics of $\mathrm{RBC}$, but when the shear rate increases, $\mathrm{RBC}$ orient in the flow direction and aggregation is reduced. Although accompanied by the disruption of the aggregates of $\mathrm{RBC}$ at high shear rates, it is the deformability of RBC that becomes the main cause of the viscoelastic properties of blood.

Vlastos et al. (1997) investigated the blood response in steady and in SAOS using a strain amplitude sweep at a constant frequency of $0.5 \mathrm{~Hz}$, as well as under a frequency sweep at constant strain amplitude. Constant steady shear rates were superimposed during oscillatory shear measurements in order to analyze their combined effect on the viscoelastic characteristics. The authors observed that increasing the steady shear rate component leads to a decrease of both viscous and elastic components due to the reduction of RBC aggregation by a non-zero average shear rate with the elastic component experiencing the highest decrease. Thurston and Henderson (2007) determined the Maxwell

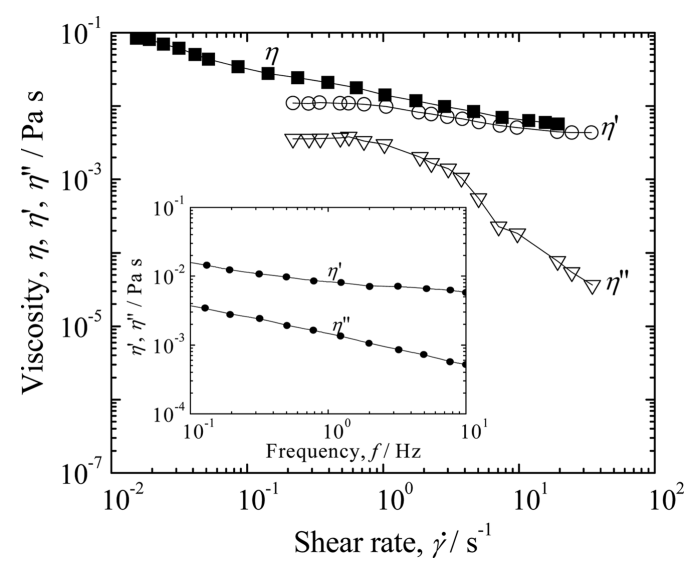

Fig. 11. Steady shear viscosity and viscous and elastic components of the complex viscosity as a function of shear rate at a frequency of oscillation, $f=2 \mathrm{~Hz}$. In the inset, viscous and elastic components of the complex viscosity are presented as a function of frequency of oscillation. Adapted from Thurston $(1979,1996)$. relaxation times of blood samples $(H c t=44 \%)$ from oscillatory measurements at $2 \mathrm{~Hz}$ and $22^{\circ} \mathrm{C}$ and showed how the blood characteristic time scale is associated with the structure and breakup of RBC aggregates (Thurston, 1979). As depicted in Fig. 12, the Maxwell relaxation time reaches a plateau at low shear rates, which is explained by the formation of RBC aggregates. When the shear rate is increased, the cell aggregates become progressively smaller and relax faster. For high shear rates, the aggregates no longer exist and the RBC deform and align with the flow leading to a further decrease of the relaxation time (Thurston and Henderson, 2007).

Thurston and Henderson (2006) showed experimentally that the Maxwell relaxation time increases when the cell deformability is decreased and the aggregation is increased, as in pathologic blood. Moreover, the influence of the flow geometry on blood viscoelasticity was also investigated by the same authors, who found that in small vessels, represented by microtubes, the elastic component of the complex viscosity increases for high shear rates, showing a shear-thickening behavior.

Recently, Campo-Deaño et al. (2013) used passive microrheology to measure the storage and loss moduli of whole blood at $27^{\circ} \mathrm{C}$ and $\mathrm{Hct}=44 \%$, confirming the non-negligible elastic behavior of whole blood (cf. Fig. 13).

\subsubsection{Large amplitude oscillatory shear measurements (LAOS)}

Sousa et al. (2013) recently investigated the response of whole human blood under LAOS. Strain amplitudes of 10, 50 and 100 were imposed and the measurements were performed at the physiological temperature, $T=37^{\circ} \mathrm{C}$. Lissajous-Bowditch plots were used to quantify the nonlinear viscoelastic properties and to determine the parameters that relate the shear stress response of the blood sample with strain or shear rate. These parameters, presented in Table 6, are the minimum elastic modulus $\left(G_{M}^{\prime}\right)$, the large

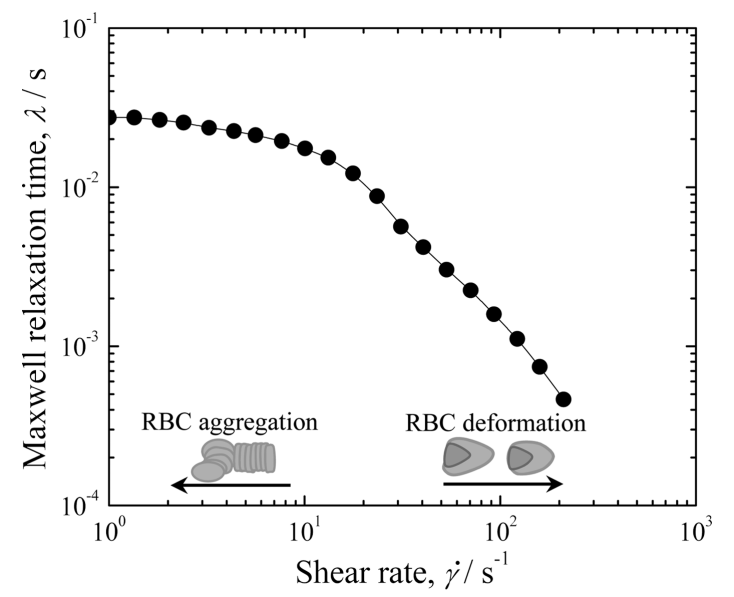

Fig. 12. Maxwell relaxation times for $H c t=44 \%$, at $f=2 \mathrm{~Hz}$ and $T=22^{\circ} \mathrm{C}$. Adapted from Thurston and Henderson (2007). 
A review of hemorheology: Measuring techniques and recent advances

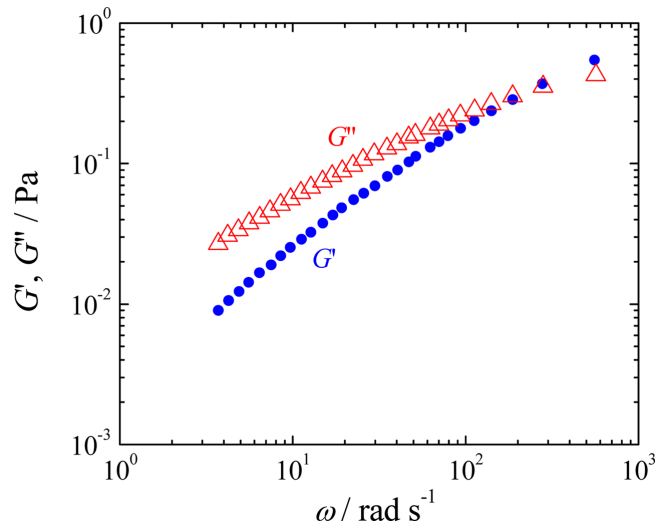

Fig. 13. (Color online) Storage $\left(G^{\prime}\right)$ and loss $\left(G^{\prime \prime}\right)$ moduli as a function of the angular frequency measured using passive microrheology for $H c t=44 \%$ and $T=27^{\circ} \mathrm{C}$. Reproduced with permission from Campo-Deaño et al. (2013).

strain elastic shear modulus $\left(G_{L}^{\prime}\right)$, the minimum-rate dynamic $\left(\eta_{M}^{\prime}\right)$ and large-rate dynamic viscosities $\left(\eta_{L}^{\prime}\right)$, the strain-stiffening ratio $(S)$ and the shear-thickening ratio $(T)$. The elastic shear moduli $\left(G_{M}^{\prime}, G_{L}^{\prime}\right)$ represent the local elastic response of a sample at small and large instantaneous strains and the minimum and large-rate dynamic viscosities $\left(\eta_{M}^{\prime}, \eta_{L}^{\prime}\right)$ give information about the instantaneous viscosities at the smallest and largest shear rates of an oscillatory test, respectively. Further details of the physical meaning of these parameters can be found in Ewoldt et al. (2008) and Hyun et al. (2011). For the rheological conditions investigated, whole blood revealed intra-cycle strain-stiffening $(S>0)$ and intra-cycle shearthinning behavior $(T>0)$. The Lissajous-Bowditch plots of $\tau(\gamma)$ and $\tau(\dot{\gamma})$ presented in Fig. 14 for an angular frequency of $0.1 \mathrm{rad} \mathrm{s}^{-1}$ illustrate the viscoelastic character of blood, since the internal area of $\tau(\gamma)$ and $\tau(\dot{\gamma})$ represent the loss and storage energies, respectively. For the higher strain amplitudes tested (50 and 100), the nearly circular shape of the $\tau(\gamma)$ plots reveal a dominant viscous behavior, which is confirmed by the small internal area of the $\tau(\gamma)$ plot. For the lower strain amplitude tested, $\gamma=10$, both Lissajous-Bowditch plots demonstrate a viscous and elastic character, but the viscous effects are still dominant.

These rheological data were recently used by Apostolidis et al. (2015) for validation purposes of a blood flow model in the transient shear regime. Their viscoelastic model captured the main features observed experimentally
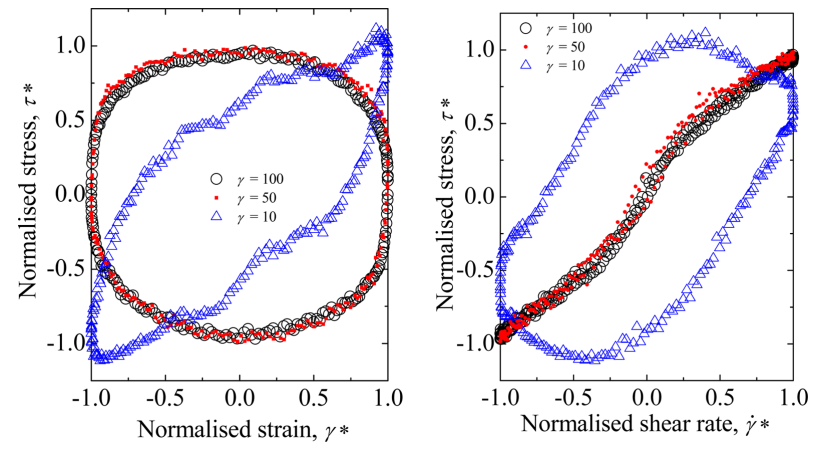

Fig. 14. (Color online) Lissajous-Bowditch plots of shear stress $v s$. strain and shear stress $v s$. shear rate at strain amplitudes $\gamma=10$, 50 and 100 and for a constant angular frequency, $\omega=0.1 \mathrm{rad} \mathrm{s}^{-1}$. Reproduced with permission from Sousa et al. (2013). The authors employed a Fourier transform analysis to describe the results and normalized the data presented in the Lissajous-Bowditch plots using the first harmonic of the Fourier series.

by Sousa et al. (2013) for both elastic and viscous components of blood, when the amplitude or frequency of oscillation was varied. However, due to its simplicity and the use of a number of fitting parameters, which were not always obtained from experimental data, only a semiquantitative agreement between the results of both investigations is observed. Additionally, the viscoelastic model was able to capture the thixotropic behavior of blood, but has a limited region of applicability, working only at low to moderate shear rates $\left(j \sim 1 \mathrm{~s}^{-1}\right)$ due to the isotropic microstructure assumed for blood.

\subsubsection{Extensional flow measurements}

It is well known that extensional properties should also be considered in the rheological characterization of complex fluids, as for example in DNA or polymer solutions (Larson, 2005). In particular, it is of utmost interest to determine the relaxation time of whole blood in extensional flow to complement the existing rheological shear data. For example, Sousa et al. (2011) investigated the flow of two well-established blood analogue solutions through micro-contractions, and showed that despite their similar steady shear viscosity curves, their behavior is significantly different when subjected to extensional flow conditions comparable to those in the microcirculation. In this respect, it is important to note the scarcity of works investigating the flow behavior of blood under extensional

Table 6. Elastic moduli $\left(G_{M}^{\prime}\right.$ and $\left.G_{L}^{\prime}\right)$, dynamic viscosities ( $\eta_{M}^{\prime}$ and $\left.\eta_{L}^{\prime}\right)$ and dimensionless indices of nonlinearity $(S$ and $T)$ obtained by Sousa et al. (2013) for two different strain amplitudes and angular velocities.

\begin{tabular}{cccccccc}
\hline \hline$\gamma$ & $\omega$ & $G_{M}^{\prime}$ & $G_{L}^{\prime}$ & $S$ & $\eta_{M}^{\prime}$ & $\eta_{L}^{\prime}$ & $T$ \\
{$[-]$} & {$\left[\mathrm{rad} \mathrm{s}^{-1}\right]$} & {$[\mathrm{Pa}]$} & {$[\mathrm{Pa}]$} & {$[-]$} & {$[\mathrm{Pa} \cdot \mathrm{s}]$} & {$[-]$} & {$\left[.61 \times 10^{-2}\right.$} \\
\hline $\mathbf{1 0}$ & $\mathbf{0 . 1 5 8}$ & $2.50 \times 10^{-3}$ & $5.84 \times 10^{-3}$ & 0.572 & $1.77 \times 10^{-2}$ & -0.100 \\
$\mathbf{1 0 0}$ & $\mathbf{1 . 0}$ & $-6.50 \times 10^{-4}$ & $-7.50 \times 10^{-4}$ & 0.133 & $4.04 \times 10^{-3}$ & $2.85 \times 10^{-3}$ & -0.417 \\
\hline
\end{tabular}


flows. To the best of our knowledge, the only investigation of the relaxation time of human whole blood in extensional flow is the recent work of Brust et al. (2013), where a characteristic CaBER relaxation time $\lambda_{c}=7.8 \pm 0.6 \mathrm{~ms}$ at $37^{\circ} \mathrm{C}$ is reported. However, no details of the measurements are provided and a more detailed investigation of this property, involving different physiological parameters, is still lacking. Interestingly, the authors found clear evidence of viscoelastic behavior when the blood plasma was subjected to elongational flow in a capillary breakup extensional rheometer. On the other hand, under steady shear flow, the human plasma showed a constant shear viscosity suggesting a Boger-like behavior, but evidence of viscoelastic behavior was also observed in microfluidic experiments using a contraction/expansion geometry. Brust et al. (2013) confirmed that viscoelastic behavior is not due to a protein surface layer but rather due to the elongational properties of the proteins, similarly to the phenomenon that occurs when adding a small amount of polymer to a solvent (Sousa et al., 2010) or even to a suspension (comparable to whole blood) (Barnes, 2003) conferring a slight viscoelastic behavior. Investigating the whole blood behavior under strong elongational flow will certainly bring better insight about its elastic nature.

\section{Concluding Remarks and Future Directions}

This review summarizes fundamental concepts and important investigations on hemorheology. The main factors that can lead to an alteration of blood rheology, and which have a significant impact on the normal physiological behavior of blood, are discussed. Quantitative comparisons of different studies are also provided in tabular form. A deviation of the whole blood viscosity from normal values can be linked with specific diseases, thus making blood viscosity a material function that can be used to identify various pathologies. Blood exhibits viscoelastic characteristics but these properties have been less investigated. The vast majority of viscoelastic measurements were performed under steady and small amplitude oscillatory shear flow conditions. Blood characterization under extensional flow and large amplitude oscillatory shear flow has been investigated only recently despite the recognized relevance of these nonlinear canonical flows in hemodynamics, e.g. LAOS measurements are relevant as pulsating blood flow under normal flow conditions is subject to large amplitude deformations.

Due to the complexity of blood flow, some simplifications are frequently assumed in hemodynamic studies. A significant number of investigations consider blood as a Newtonian fluid in spite of its non-Newtonian properties being well documented in the literature, while some works focus on cell behavior rather than on whole blood flow. Nevertheless, there has been a growing interest and increased efforts devoted to the investigation of whole blood rheological behavior under more realistic flow conditions.

Blood flow in small vessels shows complex flow features not observed at the macro-scale with enhanced nonNewtonian fluid flow characteristics, such as viscoelasticity. The increasing interest in microfluidics and the advances in the field in recent years, motivated among others by the development of micro-devices in the medical field, constitute an interesting framework for hemodynamic experiments. Furthermore, lab-on-a-chip technology combines portability, integration and automation in a single chip, and is thus a promising platform for point-of-care devices, which may be particularly useful for detection and diagnosis of circulatory disorders.

Despite notorious advances there are still many important research challenges and opportunities to be explored in hemorheology, including better characterization and deeper understanding of the behavior of individual components of blood such as the rheology of plasma and whole blood under different flow conditions, and in particular in diseased states to improve diagnostics, but also in terms of instrumentation and methodologies, in order to translate the measurements and simulations performed in research laboratories into a clinical context. In the near future, it will be possible to move toward the development and implementation of novel clinical micro-devices to be employed in medical diagnosis of hematological and cardiovascular diseases. However, there are still several fundamental topics that require further investigation for these applications to become routine:

i) Plasma rheology under extensional flow conditions. Recent investigations showed a viscoelastic behavior in extensional flow, and constant viscosity in shear flow measurements (Brust et al., 2013). Further insight into plasma rheology in extensional flow and in combined shear and extensional flow is required in order to better characterize its rheological behavior.

ii) Whole blood rheology in extensional flow or in combined shear and extensional flows should also be investigated in order to better assess its viscoelastic nature. It is known that blood only has a slight elastic character (Brust et al., 2013; Sousa et al., 2013), but a thorough quantitative characterization under extensional flow is still missing. So far, a characteristic CaBER relaxation time $\lambda_{c}=7.8 \pm$ $0.6 \mathrm{~ms}$ at $37^{\circ} \mathrm{C}$ was reported (Brust et al., 2013) but a more detailed investigation of this property, involving different physiological parameters, should be carried out. In addition, studying whole blood under extensional flow will allow analyzing RBC deformability in more detail.

iii) Blood yield stress values reported so far present some inconsistences due to the different methods used for measuring this property in addition to the inherent variability 
because of its dependency on physiological conditions. Further investigations of this property under well controlled conditions, in particular using direct measurements, are needed to obtain more accurate values and unveil the reasons for these inconsistencies.

iv) Red blood cell aggregation, which is of the upmost importance in hemodynamics, is not yet fully understood. Unraveling the mechanism involved in cell adhesion and consequently in rouleaux formation remains an important challenge. A recent study shows that dextran-induced RBC aggregation is explained based on depletion effects (Steffen et al., 2013) but consideration of other macromolecules, in particular fibrinogen, an important plasma constituent, is still lacking. The same study indicates that bridging effects can describe the adhesion mechanisms for contact times longer than a few seconds, which needs to be confirmed.

v) $\mathbf{R B C}$ deformability. Since it is now recognized that several pathologies lead to alteration of the mechanical properties of RBC and to changes of blood rheology, investigating RBC deformability and blood rheological properties of unhealthy human blood in shear and extensional flows, with control of the disease condition, is needed to develop diagnostic procedures. For example, microfluidic devices composed of hyperbolic shaped contractions (Lee et al., 2009; Yaginuma et al., 2013) have been used to investigate normal and altered RBC. Other fluidic devices with customized shapes can be used to generate different (and relevant) flow conditions in which RBC are stretched. In particular, microfluidic devices that offer easy and inexpensive fabrication have great potential to be used in the assessment of RBC behavior.

vi) Micro-rheological studies. The small samples employed in these techniques make them very interesting for blood characterization, but it should be investigated how far these can be used for the measurement of rheological properties, in spite of the occurrence of the Fåhræus-Lindqvist effect. It is also important to understand how to extrapolate the rheological properties obtained to conditions in which the plasma layer is not formed. In addition, further work on blood dynamics at the micro-scale should be considered in order to capture possible flow phenomena not easily achieved at the macro-scale. Microfluidics can be a valuable platform to develop micro-total analysis systems, which combines portability and automation for a rapid and efficient analysis of a small blood sample drawn from the patient. Examples representative of its effective potential are the lab-on-a-CD systems for biochemical (Lee et al., 2011b) or electrochemical bioanalysis or blood separation (Li et al., 2013), using only whole blood volume samples of the order of $10-100 \mu \mathrm{l}$ or even a cytometry platform developed using a cell-phone (Zhu et al., 2013), to mention only a few.

\section{Acknowledgements}

P. C. Sousa thanks Fundação para a Ciência e a Tecnologia (FCT) the financial support through POPH/FSE and national funding from MEC (fellowship SFRH/BPD/75258/ 2010). M. S. N. Oliveira acknowledges the support from the U. K. Engineering and Physical sciences Research Council (EPSRC) under the auspices of grant EP/L013118/1.

\section{References}

Akers, W.J., J.M. Cupps, and M.A. Haidekker, 2005, Interaction of fluorescent molecular rotors with blood plasma proteins, Biorheology 42, 335-344.

Alexy, T., E. Pais, R.B. Wenby, W. Hogenauer, K. Toth, H.J. Meiselman, and K.R. Kensey, 2005a, Measurement of whole blood viscosity profiles via an automated viscometer: Technical details and clinical relevance, Clin. Lab. 51, 523-529.

Alexy, T., R.B. Wenby, E. Pais, L.J. Goldstein, W. Hogenauer, and H.J. Meiselman, 2005b, An automated tube-type blood viscometer: Validation studies, Biorheology 42, 237-247.

Apostolidis, A.J., M.J. Armstrong, and A.N. Beris, 2015, Modeling of human blood rheology in transient shear flows, $J$. Rheol. 59, 275-298.

Apostolidis, A.J. and A.N. Beris, 2014, Modeling of the blood rheology in steady-state shear flows, J. Rheol. 58, 607-633.

Artmann, G.M., C. Kelemen, D. Porst, G. Buldt, and S. Chien, 1998, Temperature transitions of protein properties in human red blood cells, Biophys. J. 75, 3179-3183.

Artmann, G.M., K.L.P. Sung, T. Horn, D. Whittemore, G. Norwich, and C. Shu, 1997, Micropipette aspiration of human erythrocytes induces echinocytes via membrane phospholipid translocation, Biophys. J. 72, 1434-1441.

Barbee, J.H., 1973, The effect of temperature on the relative viscosity of human blood, Biorheology 10, 1-5.

Barnes, H.A., 2000, Handbook of Elementary Rheology, Institute of Non-Newtonian Fluid Mechanics, University of Wales Aberystwyth, U.K.

Barnes, H. A., 2003, A review of the rheology of filled viscoelastic systems, In: D. M. Binding and K. Walters eds., Rheology Reviews, The British Society of Rheology, Aberystwyth, 1-36.

Baskurt, O.K., M. Boynard, G.C. Cokelet, P. Connes, B.M. Cooke, S. Forconi, F. Liao, M.R. Hardeman, F. Jung, H.J. Meiselman, G. Nash, N. Nemeth, B. Neu, B. Sandhagen, S. Shin, G. Thurston, and J.L. Wautier, 2009a, New guidelines for hemorheological laboratory techniques, Clin. Hemorheol. Microcirc. 42, 75-97.

Baskurt, O.K., M.R. Hardeman, M. Uyuklu, P. Ulker, M. Cengiz, N. Nemeth, S. Shin, T. Alexy, and H.J. Meiselman, 2009b, Comparison of three commercially available ektacytometers with different shearing geometries, Biorheology 46, 251-264.

Benis, A.M. and J. Lacoste, 1968, Study of erythrocyte aggregation by blood viscometry at low shear rates using a balance 
method, Circ. Res. 22, 29-42.

Bingham, E.C. and H. Green, 1919, Paint a plastic material and not a viscous liquid; the measurement of its mobility and yield value, Proc Am. Soc. Test. Mater. 19, 640-664.

Bishop, J.J., A.S. Popel, M. Intaglietta, and P.C. Johnson, 2001, Rheological effects of red blood cell aggregation in the venous network: A review of recent studies, Biorheology 38, 263-274.

Breedveld, V. and D.J. Pine, 2003, Microrheology as a tool for high-throughput screening, J. Mater. Sci. 38, 4461-4470.

Bremmell, K.E., A. Evans, and C.A. Prestidge, 2006, Deformation and nano-rheology of red blood cells: An AFM investigation, Colloids Surf. B 50, 43-48.

Brust, M., C. Schaefer, R. Doerr, L. Pan, M. Garcia, P.E. Arratia, and C. Wagner, 2013, Rheology of human blood plasma: Viscoelastic versus Newtonian behavior, Phys. Rev. Lett. 110, 078305.

Campo-Deaño, L., R.P.A. Dullens, D.G.A.L. Aarts, F.T. Pinho, and M.S.N. Oliveira, 2013, Viscoelasticity of blood and viscoelastic blood analogues for use in polydymethylsiloxane in vitro models of the circulatory system, Biomicrofluidics 7, 034102.

Campo-Deaño, L., M.S.N. Oliveira, and F.T. Pinho, 2015, A review of computational hemodynamics in middle cerebral aneurysms and rheological models for blood flow, Appl. Mech. Rev. 67, 030801.

Caro, C.G., T.J. Pedley, and W.A. Seed, 1974, Mechanics of the circulation, In: A. C. Guyton ed., Cardiovascular Physiology, Medical and Technical Publishers, London, 394-395.

Charm, S.E. and G.S. Kurland, 1967, Static method for determining blood yield stress, Nature 216, 1121-1123.

Cheng, D.C.H. and F. Evans, 1965, Phenomenological characterization of rheological behaviour of inelastic reversible thixotropic and antithixotropic fluids, Brit. J. Appl. Phys. 16, 15991617.

Chien, S., 1970, Shear dependence of effective cell volume as a determinant of blood viscosity, Science 168, 977-979.

Chien, S., S. Usami, H.M. Taylor, J.L. Lundberg, and M.I. Gregerse, 1966, Effects of hematocrit and plasma proteins on human blood rheology at low shear rates, J. Appl. Physiol. 21, 81-87.

Cho, Y.I. and D.J. Cho, 2011, Hemorheology and microvascular disorders, Korean Circ. J. 41, 287-295.

Cokelet, G.R. and H.J. Meiselman, 2007, Macro- and micro-rheological properties of blood, In: O.K. Baskurt, M.R. Hardeman, M.W. Rampling, and H.J. Meiselman, eds., Handbook of Hemorheology and Hemodynamics, IOS Press, Amsterdam, 45-71.

Dao, M., C.T. Lim, and S. Suresh, 2003, Mechanics of the human red blood cell deformed by optical tweezers, J. Mech. Phys. Solids 51, 2259-2280.

Dintenfass, L., 1979, Clinical applications of blood-viscosity factors and functions-especially in the cardiovascular disorders, Biorheology 16, 69-84.

Dintenfass, L., 1985, Blood viscosity, Hyperviscosity \& Hyperviscosaemia, MTP Press, Boston.

Dobbe, J.G.G., M.R. Hardeman, G.J. Streekstra, and C.A. Grimbergen, 2004, Validation and application of an automated rheoscope for measuring red blood cell deformability distributions in different species, Biorheology 41, 65-77.

Drasler, W.J., C.M. Smith, and K.H. Keller, 1989, Viscoelastic properties of the oxygenated sickle erythrocyte-membrane, Biorheology 26, 935-949.

Eguchi, Y. and T. Karino, 2008, Measurement of rheologic property of blood by a falling-ball blood viscometer, Ann. Biomed. Eng. 36, 545-553.

Eugster, M., K. Hausler, and W.H. Reinhart, 2007, Viscosity measurements on very small capillary blood samples, Clin. Hemorheol. Microcirc. 36, 195-202.

Ewoldt, R.H., A.E. Hosoi, and G.H. McKinley, 2008, New measures for characterizing nonlinear viscoelasticity in large amplitude oscillatory shear, J. Rheol. 52, 1427-1458.

Fåhræus, R., 1929, The suspension stability of the blood, Physiol. Rev. 9, 241-274.

Fåhræus, R. and T. Lindqvist, 1931, The viscosity of the blood in narrow capillary tubes, Am. J. Physiol. 96, 562-568.

Faivre, M., M. Abkarian, K. Bickraj, and H.A. Stone, 2006, Geometrical focusing of cells in a microfluidic device: An approach to separate blood plasma, Biorheology 43, 147-159.

Fischer, T.M., M. Stohr-Lissen, and H. Schmid-Schönbein, 1978, The red cell as a fluid droplet: tank tread-like motion of the human erythrocyte membrane in shear flow, Science 202, 894896.

Fontes, A., M.L.B. Castro, M.M. Brandão, H.P. Fernandes, A.A. Thomaz, R.R. Huruta, L.Y. Pozzo, L.C. Barbosa, F.F. Costa, S.T.O. Saad, and C.L. Cesar, 2011, Mechanical and electrical properties of red blood cells using optical tweezers, J. Opt. 13, 044012.

Haidekker, M.A., A.G. Tsai, T. Brady, H.Y. Stevens, J. A. Frangos, E. Theodorakis, and M. Intaglietta, 2002, A novel approach to blood plasma viscosity measurement using fluorescent molecular rotors, Am. J. Physiol.-Heart Circul. Physiol. 282, H1609-H1614.

Harkness, J., 1971, The viscosity of human blood plasma; its measurement in health and disease, Biorheology 8, 171-193.

Hess, W.R., 1915, Does blood obey the general streaming-law of liquids?, Pflug. Arch. Ges. Phys. 162, 187-224.

Hyun, K., M. Wilhelm, C.O. Klein, K.S. Cho, J.G. Nam, K.H. Ahn, S.J. Lee, R.H. Ewoldt, and G.H. McKinley, 2011, A review of nonlinear oscillatory shear tests: Analysis and application of large amplitude oscillatory shear (LAOS), Prog. Polym. Sci. 36, 1697-1753.

International Committee for Standardisation in Haematology, 1984, Recommendation for a selected method for the measurement of plasma viscosity, J. Clin. Pathol. 37, 1147-1152.

Jan, K.M., S. Chien, and J.T.J. Bigger, 1975, Observations on blood viscosity changes after acute myocardial infarction, Circulation 51, 1079-1084.

Johnn, H., C. Phipps, S. Gascoyne, C. Hawkey, and M.W. Rampling, 1992, A comparison of the viscometric properties of the blood from a wide-range of mammals, Clin. Hemorheol. 12, 639-647.

Kang, Y.J. and S.J. Lee, 2013, Blood viscoelasticity measurement using steady and transient flow controls of blood in a microfluidic analogue of Wheastone-bridge channel, Biomicrofluidics 7. Kang, Y.J. and S. Yang, 2013, Integrated microfluidic viscometer 
A review of hemorheology: Measuring techniques and recent advances

equipped with fluid temperature controller for measurement of viscosity in complex fluids, Microfluid. Nanofluid. 14, 657-668.

Kim, S., Y.I. Cho, A.H. Jeon, B. Hogenauer, and K.R. Kensey, 2000, A new method for blood viscosity measurement, J. NonNewton. Fluid Mech. 94, 47-56.

Koenig, W., M. Sund, B. Filipiak, A. Döring, H. Löwel, and E. Ernst, 1998, Plasma viscosity and the risk of coronary heart disease-Results from the MONICA-Augsburg cohort study, 1984 to 1992, Arterioscler. Thromb. Vasc. Biol. 18, 768-772.

Koutsouris, D., R. Guillet, J.C. Lelievre, M.T. Guillemin, P. Bertholom, Y. Beuzard, and M. Boynard, 1988, Determination of erythrocytes transit times through micropores. 1. Basic Operational Principles, Biorheology 25, 763-772.

Langstroth, L., 1919, Blood viscosity. I. Conditions affecting the viscosity of blood after withdrawal from the body, J. Exp. Med. 30, 597-606.

Larson, R.G., 2005, The rheology of dilute solutions of flexible polymers: Progress and problems, J. Rheol. 49, 1-70.

Laurent, V.M., S. Henon, E. Planus, R. Fodil, M. Balland, D. Isabey, and F. Gallet, 2002, Assessment of mechanical properties of adherent living cells by bead micromanipulation: Comparison of magnetic twisting cytometry vs optical tweezers, $J$. Biomech. Eng.-Trans. ASME 124, 408-421.

Le Devehat, C., M.Vimeux, and T. Khodabandehlou, 2004, Blood rheology in patients with diabetes mellitus, Clin. Hemorheol. Microcirc. 30, 297-300.

Lee, B.K., T. Alexy, R.B. Wenby, and H.J. Meiselman, 2007, Red blood cell aggregation quantitated via Myrenne aggregometer and yield shear stress, Biorheology 44, 29-35.

Lee, B.K., S. Xue, J. Nam, H. Lim, and S. Shin, 2011a, Determination of the blood viscosity and yield stress with a pressure-scanning capillary hemorheometer using constitutive models, Korea-Aust. Rheol. J. 23, 1-6.

Lee, B.S., Y.U. Lee, H.S. Kim, T.H. Kim, J. Park, J.G. Lee, J. Kim, H. Kim, W.G. Lee, and Y.K. Cho, 2011b, Fully integrated lab-on-a-disc for simultaneous analysis of biochemistry and immunoassay from whole blood, Lab Chip 11, 70-78.

Lee, S.S., Y. Yim, K.H. Ahn, and S.J. Lee, 2009, Extensional flow-based assessment of red blood cell deformability using hyperbolic converging microchannel, Biomed. Microdevices 11, 1021-1027.

Li, T., Y. Fan, Y. Cheng, and J. Yang, 2013, An electrochemical lab-on-a-CD system for parallel whole blood analysis, Lab. Chip. 13, 2634-2640.

Li, X.J., Z.L. Peng, H. Lei, M. Dao, and G.E. Karniadakis, 2014, Probing red blood cell mechanics, rheology and dynamics with a two-component multi-scale model, Philos. Trans. R. Soc. A 372.

Li, Y.J., C. Wen, H.M. Xie, A.P. Ye, and Y.J. Yin, 2009, Mechanical property analysis of stored red blood cell using optical tweezers, Colloid Surf. B 70, 169-173.

Lim, C.T., M. Dao, S. Suresh, C.H. Sow, and K.T. Chew, 2004, Large deformation of living cells using laser traps, Acta Mater. 52, 1837-1845.

Lim, H.J., Y.J. Lee, J.H. Nam, S. Chung, and S. Shin, 2010, Temperature-dependent threshold shear stress of red blood cell aggregation, J. Biomech. 43, 546-550.

Lo Presti, R., E. Hopps, and G. Caimi, 2014, Hemorheological abnormalities in human arterial hypertension, Korea-Aust. Rheol. J. 26, 199-204.

Marcinkowska-Gapinska, A., J. Gapinski, W. Elikowski, F. Jaroszyk, and L. Kubisz, 2007, Comparison of three rheological models of shear flow behavior studied on blood samples from post-infarction patients, Med. Biol. Eng. Comput. 45, 837-844.

Mark, M., K. Hausler, J. Dual, and W.H. Reinhart, 2006, Oscillating viscometer-Evaluation of a new bedside test, Biorheology 43, 133-146.

Marton, Z., G. Kesmarky, J. Vekasi, A. Cser, R. Russai, B. Horvath, and K. Toth, 2001, Red blood cell aggregation measurements in whole blood and in fibrinogen solutions by different methods, Clin. Hemorheol. Microcirc. 24, 75-83.

Merrill, E.W., 1969, Rheology of blood, Physiol. Rev. 49, 863-888. Merrill, E.W., H. Shin, G. Cokelet, E.R. Gilliland, R.E. Wells, and A. Britten, 1963, Rheology of human blood, near and at zero flow - Effects of temperature and hematocrit level, Biophys. J. 3, 199-213.

Mills, J.P., M. Diez-Silva, D.J. Quinn, M. Dao, M.J. Lang, K.S.W. Tan, C.T. Lim, G. Milon, P.H. David, O. Mercereau-Puijalon, S. Bonnefoy, and S. Suresh, 2007, Effect of plasmodial RESA protein on deformability of human red blood cells harboring Plasmodium falciparum, Proc. Natl. Acad. Sci. U.S.A. 104, 92139217.

Moreno, L., F. Calderas, G. Sanchez-Olivares, L. Medina-Torres, A. Sanchez-Solis, and O. Manero, 2015, Effect of cholesterol and triglycerides levels on the rheological behavior of human blood, Korea-Aust. Rheol. J. 27, 1-10.

Morris, C.L., C.M. Smith, and P.L. Blackshear, 1987, A new method for measuring the yield stress in thin-layers of sedimenting blood, Biophys. J. 52, 229-240.

Muramoto, Y. and Y. Nagasaka, 2011, High-speed sensing of microliter-order whole-blood viscosity using laser-induced capillary wave, J. Biorheology 25, 43-51.

Neuman, K.C. and A. Nagy, 2008, Single-molecule force spectroscopy: optical tweezers, magnetic tweezers and atomic force microscopy, Nat. Methods 5, 491-505.

Ong, P.K., D. Lim, and S. Kim, 2010, Are microfluidics-based blood viscometers ready for point-of-care applications? A review, Crit. Rev. Biomed. Eng. 38, 189-200.

Owens, R.G., 2006, A new micro structure-based constitutive model for human blood, J. Non-Newton. Fluid Mech. 140, 57-70.

Picart, C., P.H. Carpentier, H. Galliard, and J.M. Piau, 1999, Blood yield stress in systemic sclerosis, Am. J. Physiol.-Heart Circul. Physiol. 276, H771-H777.

Picart, C., J.M. Piau, H. Galliard, and P. Carpentier, 1998, Human blood shear yield stress and its hematocrit dependence, $J$. Rheol. 42, 1-12.

Pirofsky, B., 1953, The determination of blood viscosity in man by a method based on Poiseuille's law, J. Clin. Invest. 32, 292-298.

Popel, A.S. and P.C. Johnson, 2005, Microcirculation and hemorheology, Annu. Rev. Fluid Mech. 37, 43-69.

Pozrikidis, C., 2003, Modeling and Simulation of Capsules and Biological Cells, CRC Press, Boca Raton.

Puig-De-Morales-Marinkovic, M., K.T. Turner, J.P. Butler, J.J. Fredberg, and S. Suresh, 2007, Viscoelasticity of the human red blood cell, Am. J. Physiol.: Cell Physiol. 293, C597-C605. 
Radtke, H., R. Schneider, R. Witt, H. Kiesewetter, and H. SchmidSchönbein, 1984, A measuring device to determine a universal parameter for the flow characteristics of blood: measurement of the yield shear stress in a branched capillary, Adv. Exp. Med. Biol. 169, 851-857.

Rampling, M.W., 2007, Compositional properties of blood, In: O.K. Baskurt, M.R. Hardeman, M.W. Rampling, and H.J. Meiselman, eds., Handbook of Hemorheology and Hemodynamics, IOS Press, Amsterdam, 34-44.

Replogle, R.L., H.J. Meiselman, and E.W. Merrill, 1967, Clinical implications of blood rheology studies, Circulation 36, 148160.

Rosencranz, R. and S.A. Bogen, 2006, Clinical laboratory measurement of serum, plasma, and blood viscosity, Am. J. Clin. Pathol. 125, S78-86.

Schmid-Schönbein, H., P. Gaehtgens, and H. Hirsch, 1968, On the shear rate dependence of red cell aggregation in vitro, $J$. Clin. Invest. 47, 1447-1454.

Secomb, T.W., 1987, Flow-dependent rheological properties of blood in capillaries, Microvasc. Res. 34, 46-58.

Sharma, K. and S.V. Bhat, 1992, Non-Newtonian rheology of leukemic blood and plasma: are $\mathrm{n}$ and $\mathrm{k}$ parameters of power law model diagnostic?, Physiol. Chem. Phys. Med. NMR 24, 307-312.

Shin, S., J.X. Hou, J.S. Suh, and M. Singh, 2007, Validation and application of a microfluidic ektacytometer (RheoScan-D) in measuring erythrocyte deformability, Clin. Hemorheol. Microcirc. 37, 319-328.

Shin, S., S.W. Lee, and Y.L. Ku, 2004, Measurements of blood viscosity using a pressure-scanning slit viscometer, KSME Int. J. 18, 1036-1041.

Shung, K.K., 2006, Diagnostic Ultrasound : Imaging and Blood Flow Measurements, CRC Press, Boca Raton.

Simchon, S., K. M. Jan, and S. Chien, 1987, Influence of Reduced Red-Cell Deformability on Regional Blood-Flow, Am. J. Physiol. 253, H898-H903.

Smith, P.D., R.C.D. Young, and C.R. Chatwin, 2010, A MEMS viscometer for unadulterated human blood, Measurement 43, 144-151.

Sousa, P.C., J. Carneiro, F.T. Pinho, M.S.N. Oliveira, and M.A. Alves, 2013, Steady and large-oscillatory shear rheology of whole blood, Biorheology 50, 269-282.

Sousa, P.C., F.T. Pinho, M.S.N. Oliveira, and M.A. Alves, 2010, Efficient microfluidic rectifiers for viscoelastic fluid flow, $J$. Non-Newton. Fluid Mech. 165, 652-671.

Sousa, P.C., F.T. Pinho, M.S.N. Oliveira, and M.A. Alves, 2011, Extensional flow of blood analog solutions in microfluidic devices, Biomicrofluidics 5, 014108-014119.

Squires, T.M. and T.G. Mason, 2010, Fluid mechanics of microrheology, Annu. Rev. Fluid Mech. 42, 413-438.

Srivastava, N., R.D. Davenport, and M.A. Burns, 2005, Nanoliter viscometer for analyzing blood plasma and other liquid samples, Anal. Chem. 77, 383-392.

Steffen, P., C. Verdier, and C. Wagner, 2013, Quantification of depletion-induced adhesion of red blood cells, Phys. Rev. Lett. 110, 018102-018105.
Sutera, S.P. and R. Skalak, 1993, The history of Poiseuille law, Annu. Rev. Fluid Mech. 25, 1-19.

Taguchi, Y., R. Nagamachi, and Y. Nagasaka, 2009, Micro optical viscosity sensor for in situ measurement based on a laserinduced capillary wave, J. Therm. Sci. Technol. 4, 98-108.

Thiriet, M., 2008, Biology and Mechanics of Blood Flows, Springer, New York.

Thurston, G.B., 1972, Viscoelasticity of human blood, Biophys. J. 12, 1205-1217.

Thurston, G.B., 1979, Rheological parameters for the viscosity viscoelasticity and thixotropy of blood, Biorheology 16, 149-162.

Thurston, G.B., 1996, Viscoelastic properties of blood and blood analogs, In: T.V. How ed., Advances in Hemodynamics and Hemorheology, Vol. 1, JAI Press LTD., London, 1-30.

Thurston, G.B. and N.M. Henderson, 2006, Effects of flow geometry on blood viscoelasticity, Biorheology 43, 729-746.

Thurston, G.B. and N.M. Henderson, 2007, Viscoelasticity of human blood, In: O.K. Barskurt, M.R. Hardeman, M.W. Rampling, and H.J. Meiselman, eds., Handbook of Hemorheology and Hemodynamics, IOS Press, Amsterdam, 72-90.

Travagli, V., I. Zanardi, L. Boschi, A. Gabbrielli, V.A.M. Mastronuzzi, R. Cappelli, and S. Forconi, 2008, Comparison of blood viscosity using a torsional oscillation viscometer and a rheometer, Clin. Hemorheol. Microcirc. 38, 65-74.

Valant, A. Z., L. Ziberna, Y. Papaharilaou, A. Anayiotos and G. C. Georgiou, 2011, The influence of temperature on rheological properties of blood mixtures with different volume expanders-implications in numerical arterial hemodynamics simulations, Rheol. Acta 50, 389-402.

Vlastos, G., D. Lerche, B. Koch, O. Samba, and M. Pohl, 1997, The effect of parallel combined steady and oscillatory shear flows on blood and polymer solutions, Rheol. Acta 36, 160-172.

Waite, L., 2006, Biofluid Mechanics in Cardiovascular Systems, McGraw-Hill, New York.

Yaginuma, T., M.S. Oliveira, R. Lima, T. Ishikawa, and T. Yamaguchi, 2013, Human red blood cell behavior under homogeneous extensional flow in a hyperbolic-shaped microchannel, Biomicrofluidics 7, 054110.

Yao, A., M. Tassieri, M. Padgett, and J. Cooper, 2009, Microrheology with optical tweezers, Lab Chip 9, 2568-2575.

Yilmaz, F. and M.Y. Gundogdu, 2008, A critical review on blood flow in large arteries; relevance to blood rheology, viscosity models, and physiologic conditions, Korea-Aust. Rheol. J. 20 , 197-211.

Zeng, H. and Y. Zhao, 2009, On-chip blood viscometer towards point-of-care hematological diagnosis, 22nd IEEE International Conference, Sorento.

Zhu, H.Y., I. Sencan, J. Wong, S. Dimitrov, D. Tseng, K. Nagashima and A. Ozcan, 2013, Cost-effective and rapid blood analysis on a cell-phone, Lab Chip 13, 1282-1288.

Zydney, A.L., J.D. Oliver, and C.K. Colton, 1991, A constitutive equation for the viscosity of stored red-cell suspensions-Effect of hematocrit, shear rate, and suspending phase, J. Rheol. 35, $1639-1680$. 